Article

\title{
Welding of Dissimilar Steel/Al Joints Using Dual-Beam Lasers with Side-by-Side Configuration
}

\author{
Li Cui *, Hongxi Chen, Boxu Chen and Dingyong He * \\ College of Materials Science and Engineering, Beijing University of Technology, 100\# Pingleyuan, \\ Chaoyang District, Beijing 100124, China; chx@emails.bjut.edu.cn (H.C.); thecbx92@emails.bjut.edu.cn (B.C.) \\ * Correspondence: cuili@bjut.edu.cn (L.C.); dyhe@bjut.edu.cn (D.H.); \\ Tel.: +86-10-67932523 (L.C.); +86-10-67932168 (D.H.)
}

Received: 13 November 2018; Accepted: 1 December 2018; Published: 4 December 2018

\begin{abstract}
Welding of dissimilar steel/Al lapped joints of $1.5 \mathrm{~mm}$ in thickness was carried out by using dual-beam laser welding with side-by-side configuration. The effect of the major process parameters including the dual-beam power ratio of $(R s)$ and dual-beam distance $\left(d_{1}\right)$ on the steel/Al joint characteristics was investigated concerning the weld shape, interface microstructures, tensile resistance and fracture behavior. The results show that dual-beam laser welding with side-by-side configuration produces soundly welded steel/Al lapped joints free of welding defects. The processing parameters of $R s$ and $d_{1}$ have a great influence on the weld appearance, the weld penetration in the $\mathrm{Al}$ alloy side (P2) and the welding defects. Variation in the depth of the P2 and the locations at the $\mathrm{Al}$ /weld interface cause heterogeneous microstructures in the morphology and the thickness of the intermetallic compound (IMC) layers. In addition, electron back scattered diffraction (EBSD) phase mapping reveals that the IMC layer microstructures formed at the $\mathrm{Al}$ /weld interface include the needle-like $\theta-\mathrm{Fe}_{4} \mathrm{Al}_{13}$ phases and compact lath $\eta-\mathrm{Fe}_{2} \mathrm{Al}_{5}$ layers. Some very fine $\theta-\mathrm{Fe}_{4} \mathrm{Al}_{13}$ and $\eta-\mathrm{Fe}_{2} \mathrm{Al}_{5}$ phases generated along the weld grain boundaries of the steel/ $\mathrm{Al}$ joints are also confirmed. Finally, there is a matching relationship between the P2 and the tensile resistance of steel/ $\mathrm{Al}$ joints, and the maximum tensile resistance of $109.2 \mathrm{~N} / \mathrm{mm}$ is obtained by the steel/Al joints produced at the $R s$ of 1.50 during dual-beam laser welding with side-by-side configuration. Two fracture path modes have taken place depending on the P2, and relatively high resistance has been achieved for the steel/Al joints with an optimum P2.
\end{abstract}

Keywords: dual-beam laser welding; steel/Al joint; side-by-side configuration; tensile resistance; EBSD phase mapping

\section{Introduction}

Joints between dissimilar metals are particularly common in components used in the power generation, chemical, petrochemical, nuclear, and electronics industries [1]. Current and potential dissimilar welding applications in the automotive industry include wind shield frame, center pillar, bumper reinforcement, and floor pan, among others [2]. With the increased use of dissimilar metal parts in the industry applications, joining of dissimilar joints has become increasingly important. The total weight reduction of the composite components fabricated by dissimilar joining of steels to $\mathrm{Al}$ alloys makes it attractive to various industries, such as the automotive [2-5] and shipbuilding industries [6-8]. Several welding techniques for joining dissimilar steel and $\mathrm{Al}$ metals have been reported. For example, Explosion Welding (EW) technique is used for successful joining the bimetallic plates in shipbuilding applications [7-9]. However, EW can produce high quality joints [10-12], but the cost effectiveness and mass efficiency are thus reduced in such structures [6]. Fusion-based welding processes have been recently investigated due to the flexibility compared with the EW. It has been 
reported that it is still a large challenge in the field of fusion-based welding due to the huge disparity in thermal-physical properties between steels and $\mathrm{Al}$ alloys [2-4]. The main issue associated with welding of steel/ $\mathrm{Al}$ joints is the formation of the brittle intermetallic compound (IMC) phases as a result of the reaction between iron $(\mathrm{Fe})$ and aluminum $(\mathrm{Al})$, which is detrimental to the mechanical properties of the steel/Al joints $[5,13]$. The IMC layer thickness at the interface is generally accepted with less than $10 \mu \mathrm{m}$ to avoid the degradation of the strength of the steel/ $\mathrm{Al}$ joints $[5,13,14]$.

As the formation of the IMC layers is mainly controlled by the temperature and the time [15], the welding process should have simultaneously low heat input and high cooling rate [13] for successfully joining of the steel/ $\mathrm{Al}$ joints. In this respect, laser welding offers some distinct advantages over the convention arc welding, such as high energy density, controllable heat input, accurate laser beam location, small heat-affected zones, high welding speed, to meet the increasing demands for high performance of welding of steel/Al joints [16,17]. During laser welding of steel/Al joints, three welding processes are reported involving reactive wetting, welding-brazing and keyhole welding [18]. Among these three methods, current state-of-the-art of the welding process has the main focus on welding-brazing for dissimilar metal joints, and it has been proved as one of the most effective welding methods for dissimilar metal parts $[19,20]$. However, the good wettability of molten $\mathrm{Al}$ on the solid steel [21] has been difficult to obtain, because factors such as unequal temperature distribution, rapid cooling rate, and deficient heating during laser welding-brazing deteriorated the wetting and spreading of liquid Al alloy on the steel surface [22]. To improve the wettability, a variety of filler materials or specific techniques have normally been required, such as the use of chemical flux, brazing in vacuum or inert gas atmosphere, surface preparation [21,23], which resulted in additional costs generated by the flux application and the subsequent cleaning necessary to remove all residues detrimental to corrosion resistance [21]. To avoid the wettability problems, laser keyhole welding could be utilized $[5,17,21]$, which provides very short interaction times between liquid steel and liquid Al to limit IMC phases without any filler materials [24]. This method has been of important technological interest, because it allows a reduction in joint preparation time and has fewer parameters to control, making it easier to obtain reproducible and stable results [24]. However, the laser keyhole welding presents issues related to the instability of the keyhole, which lead to excessive welding defects, such as pores and spatters [25].

To overcome the disadvantage of single-beam laser welding, dual-beam laser welding has been proposed as one of the alternative methods in some earlier research works for welding of aluminum alloys, titanium alloys, steels [26-28], etc. The original idea behind this approach, namely utilizing two individual focal spots at the workpiece instead of single beam, is to shape the keyhole by appropriate double-focus geometry such that the tendency of a keyhole collapse is considerably reduced [29]. During the dual-beam laser welding, the dual beams are arranged in either tandem or side-by-side (as shown in Figure 1a) in dual-beam laser processing [28,30]. The two beams are arranged preferably in a way that they can compensate and benefit from each other. The dual-beam configuration has been demonstrated as a key factor affecting strongly the temperature and the time at the interface of the steel/Al joints [28,31]. Dual laser beams arranged in tandem have been reported to provide benefits over conventional single-beam laser welding such as improved weld quality [26-28,32]. A study on using side-by-side laser beams for improved fit-up tolerance has been reported in welding tailored blanks [33]. The previous studies demonstrated that there was a significant difference in process efficiency between the two configurations regarding the molten seam volume per energy unit $\left(\mathrm{mm}^{3} / \mathrm{kJ}\right)$ : the molten area of the cross section in tandem configuration-meaning the second laser was following the first one-was considerably smaller than that in the side-by-side configuration $[27,29]$. 
(a)

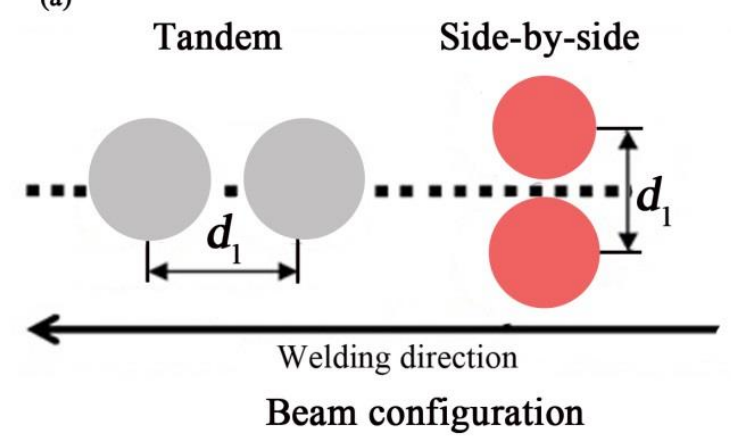

(d)

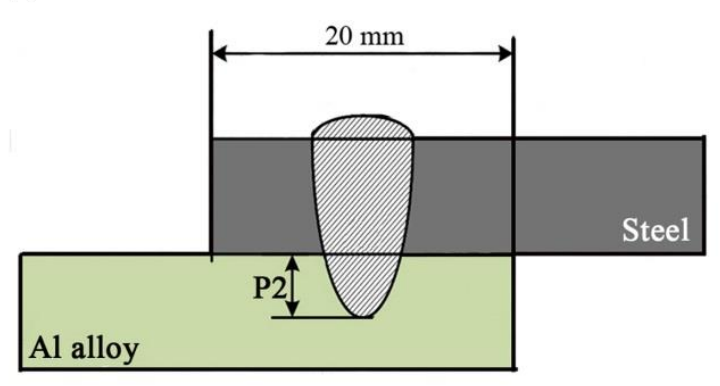

(b)

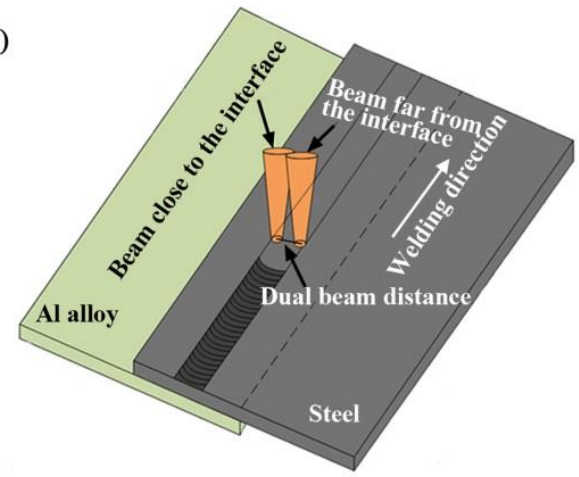

(c)

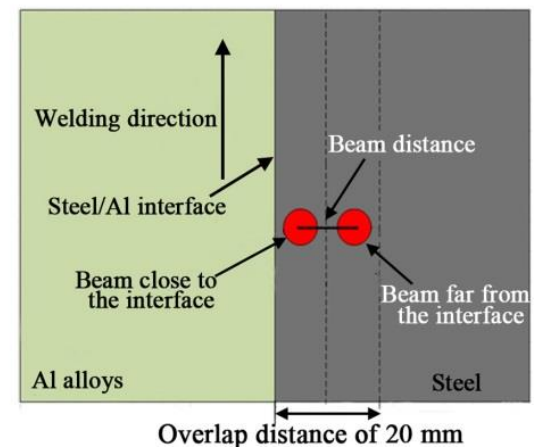

Figure 1. Schematic diagram of dual-beam laser welding of steel/Al joints: (a) Tandem beam and side-by-side configuration [28,30]; (b) Setup of the side-by-side configuration; (c) Main processing parameters with side-by-side configuration; (d) Dimension of the cross section of the welds.

Most recently, dual-beam laser welding has been introduced for dissimilar welding of steel/ $\mathrm{Al}$ joints. Laukant et al. [34] reported that the melt flow could be controlled more effectively and the wetting behavior could be improved by preheating the zinc-covered steel sheet surface with a second laser beam when joined zinc-coated steel and Al sheets in overlap geometry. Shi et al. [35] demonstrated that the application of a dual-beam laser keyhole welding could generate an acceptable steel/Al joint and effectively reduced the presence of the welding defects. Chen et al. [36] found that the dual-beam laser welding exhibited better process stability leading to better weld appearance, and bigger effective joining width, which enhanced tensile capacity. Our previous study on dual-beam laser welding of steel/Al joints with tandem configuration demonstrated that soundly welded steel/Al joints had been achieved by using dual-beam laser keyhole welding at optimum welding conditions [37]. The above studies show that dual-beam laser welding of steel/ $\mathrm{Al}$ joints maintained the key advantages of laser keyhole welding and even improved efficiently the mechanical properties of the steel/Al joints. However, these studies reported on dual-beam laser welding of steel/Al joints were limited to the tandem configuration. In addition, one new piece of research investigated the effect of dual-beam modes between tandem and side-by-side configuration on welding of steel/Al joints [38], indicating that the side-by-side configuration offered some superiority over the tandem one. This cited study has yielded some important knowledge on the possible use of dual-beam laser welding of steel/Al joints with side-by-side configuration, but the relationship between the welding parameters and weld shape have not been yet examined. However, it is important that details of processing parameters on the weld shape during the dual-beam laser welding with side-by-side configuration be well defined.

Compared to the single-beam laser welding, the dual-beam welding process provides additional process parameters, which allows for affecting the weld shape and welding quality. The dual-beam power ratio $(R s)$ and dual-beam distance $\left(d_{1}\right)$ are the most important parameters. Thus, the effect of the process parameters on the steel/ $\mathrm{Al}$ joint characteristics is essential to well understand the dual-beam laser welding of steel/Al joints. However, studies on the effect of process parameters on the weld 
shape of the steel/Al joints are scarce. Details of the effect of process parameters on the steel/ $\mathrm{Al}$ joint characteristics are still far from being completely understood.

In the present study, dual-beam laser welding of steel/Al lapped joints was conducted by means of side-by-side configuration. Effect of the $R s$ and $d_{1}$ on the weld shape, $\mathrm{Al} /$ weld interfacial microstructures, and tensile resistance and fracture behaviors of the steel/ $\mathrm{Al}$ joints were investigated. Using EBSD analysis, the phase composition, grain shape and grain size of the $\mathrm{Al} /$ weld interface microstructures with different locations were studied.

\section{Materials and Methods}

Q235 low carbon steel and $6061 \mathrm{Al}$ alloy sheets in the dimension of $150 \mathrm{~mm} \times 100 \mathrm{~mm} \times 1.5 \mathrm{~mm}$ were used in the present study. The nominal compositions of the Q235 steels and $6061 \mathrm{Al}$ alloys are listed in Table 1. Before welding, the specimen surface was polished by angle grinder and was chemically cleaned with acetone to eliminate surface contamination. The specimens were arranged in a lapped configuration with the overlap distance of $20 \mathrm{~mm}$, as shown in Figure 1b. Throughout the experiments, the welding operation was shielded by the trailing and back shielding gas supplied by purity argon at a flow rate of $20 \mathrm{~L} / \mathrm{min}$ and $15 \mathrm{~L} / \mathrm{min}$.

Table 1. Nominal chemical composition of 6061 alloys and Q235 steels (wt \%).

\begin{tabular}{ccccccccccccc}
\hline Materials & $\mathbf{M g}$ & $\mathbf{C}$ & $\mathbf{P}$ & $\mathbf{N i}$ & $\mathbf{S}$ & $\mathbf{M n}$ & $\mathbf{C r}$ & $\mathbf{F e}$ & $\mathbf{S i}$ & $\mathbf{Z n}$ & $\mathbf{T i}$ & $\mathbf{C u}$ \\
\hline $\mathbf{6 0 6 1}$ & $0.8-1.2$ & - & - & - & - & $\leq 0.15$ & $0.04-0.3$ & $\leq 0.7$ & $0.4-0.8$ & $\leq 0.25$ & $\leq 0.15$ & $0.15-0.4$ \\
Q235 & - & $\leq 0.2$ & $\leq 0.04$ & $\leq 0.3$ & $\leq 0.04$ & $0.3-0.7$ & $\leq 0.30$ & Bal. & $\leq 0.35$ & - & - & $\leq 0.30$ \\
\hline
\end{tabular}

Dual-beam laser welding was performed on steel/ Al lapped joint using a $6 \mathrm{~kW}$ YLR-6000 Yb fiber laser (IPG Photonics, Oxford, MA, USA). This fiber lasers with an emission wave length of $1070 \mathrm{~nm}$ can deliver in continuous wave mode through an output fiber core diameter of $100 \mu \mathrm{m}$. The welding system was combined by a focal length of $200 \mathrm{~mm}$ collimating lens and a focal length of $200 \mathrm{~mm}$ focusing lens. The beam diameter of the laser beam at the focal point was $0.3 \mathrm{~mm}$. The dual beams were obtained by using an optical prism put between the collimating lens and the focusing lens, and through it the single beam was split into two ones. The setup of the dual beams arranged in side-by-side configuration is illustrated in Figure $1 \mathrm{~b}$. The Rs was calculated by the ratio of the beam power close to the $\mathrm{Al} /$ weld interface to the far one, and the Rs of $0.25,0.5,0.67,1.50,2.00$ and 4.00 was tested for the welding experiments, which was determined by the dual-beam laser power fraction of 20/80 33/66, $40 / 60,60 / 40,66 / 33,80 / 20$, respectively. As a result, the dual-beam lasers with whether the smaller or the larger energy fraction will have the relatively strong asymmetric energy distribution [29]. The $d_{1}$ was defined as the distance between the two focusing spot of the beams on the surface of the welding specimens. Based on the preliminary parametric study, the $d_{1}$ of $0.5 \mathrm{~mm}, 1.0 \mathrm{~mm}, 1.5 \mathrm{~mm}$ and $2.0 \mathrm{~mm}$ were examined in details. The other welding parameters, such as, the total laser power $\left(P_{\mathrm{L}}\right)$ of $3000 \mathrm{~W}$, the travel speed $(v)$ of $33 \mathrm{~mm} / \mathrm{s}$, and the beam defocusing distance $(\Delta Z)$ of $0 \mathrm{~mm}$ were kept constant.

After welding, the welded joints were cut transversely from the welds and prepared for metallographic observation through mounting, polishing, and etching with Keller's reagent (HF:HCl: $: \mathrm{HNO}_{3}: \mathrm{H}_{2} \mathrm{O}=1: 1.5: 2.5: 95$ ) for Al alloys and 4\% Nital acid for the Q235 steels to display the weld shape. The P2 was the depth of the weld in the Al alloy side of the steel/Al joints as illustrated in Figure 1d. Microstructural analysis was performed using an optical microscope, scanning electron microscopy (SEM) and EBSD. The morphology and thickness of the IMC layers at the $\mathrm{Al} /$ weld interface were examined using SEM of QUANTA FEG 650 (FEI, Hillsboro, OR, USA). The EBSD analysis was conducted by a field emission gun Quanta FEI 650 (FEI, Hillsboro, OR, USA) SEM operated at $30 \mathrm{kV}$ and $1.0 \mathrm{~nm}$. The EBSD sample was oriented at $70^{\circ}$ tilt in the chamber at a working distance in the range from $5 \mathrm{~mm}$ to $30 \mathrm{~mm}$. Samples for EBSD with the size of $10 \times 10 \times 10 \mathrm{~mm}^{3}$ dependent on the ability of the SEM's chamber were cut, mounted, grounded, mechanically polished and subsequently, electropolished by immersion in a $30 \%$ nitric acid in methanol solution cooled to $-25^{\circ} \mathrm{C}$ at a voltage 
of $20 \mathrm{~V}$ for $30 \mathrm{~s}$. Orientation image map (OIM) and phase mapping were measured in a rectangular zone using a step size of $0.3 \mu \mathrm{m}$ between two measurements.

The tensile tests of the prepared specimens at the Rs of $0.25 \sim 4.00$ and the $d_{1}$ of $0.5 \sim 2.0 \mathrm{~mm}$ were performed in accordance with the standard of GB/T 2651-2001 using a MTS810 (MTS, Eden Prairie, MN, USA) testing machine having the maximum capacity of $100 \mathrm{kN}$ operating in a stress control mode with a load rate of $1 \mathrm{~mm} / \mathrm{min}$ at room temperatures. For the overlap configuration, the joint zone of the tensile specimens were rotated during mechanical test because two forces in the specimen were not in line, and thus a torque was generated $[17,36]$. In this case, the researchers did not evaluate whether the forces were shear or tensile, and the normalized stress at failure (based on bonded area or fracture area) was not calculated. The tensile property was supposed by expressing as the maximal load per millimeter, i.e., linear failure strength $(\mathrm{N} / \mathrm{mm})[17,24,36]$. Therefore, in the present study, the tensile resistance was evaluated by means of the linear failure strength $(\mathrm{N} / \mathrm{mm})$ as the tensile property of the steel/Al joints. The average tensile resistance value was determined by means of tensile tests carried out on 3 specimens. Fracture path and the fracture surface morphology of the fractured joints were observed using SEM.

\section{Results and Discussion}

\subsection{Weld Shape of the Steel/Al Joints}

\subsubsection{Effect of the Dual-Beam Power Ratio (Rs)}

Figure 2 shows the weld appearances of the steel/ $\mathrm{Al}$ joints produced by dual-beam laser welding with side-by-side configuration at different $R s$ varied from 0.25 to 4.00 while the $d_{1}$ of $1.0 \mathrm{~mm}$, the $P_{\mathrm{L}}$ of $3000 \mathrm{~W}$, the $v$ of $33 \mathrm{~mm} / \mathrm{s}$, and the $\Delta \mathrm{Z}$ of $0 \mathrm{~mm}$ were fixed. All the welds show regular ripples without any visible welding defects, such as cracks, pores, and so on. This was a benefit of the improved keyhole stability of dual-beam laser welding [34]. The welds exhibit uniform and smooth bead surface at the $R s$ of $0.25,0.67,1.50$ and 4.00 . However, at the $R s$ of $0.50(33 / 66)$ and $2.00(66 / 33)$, the regularity of weld and smoothness are slightly reduced, meaning the energy distribution of the dual beams at the $R s$ of $33 / 66$ or $66 / 33$ is not suitable for the weld appearance quality. Therefore, the Rs of $0.25(20 / 80)$, $0.67(40 / 60), 1.50(60 / 40)$ and $4.00(80 / 20)$ are appropriate for obtaining smooth welds of the steel/Al joints in dual-beam laser welding with side-by-side configuration.
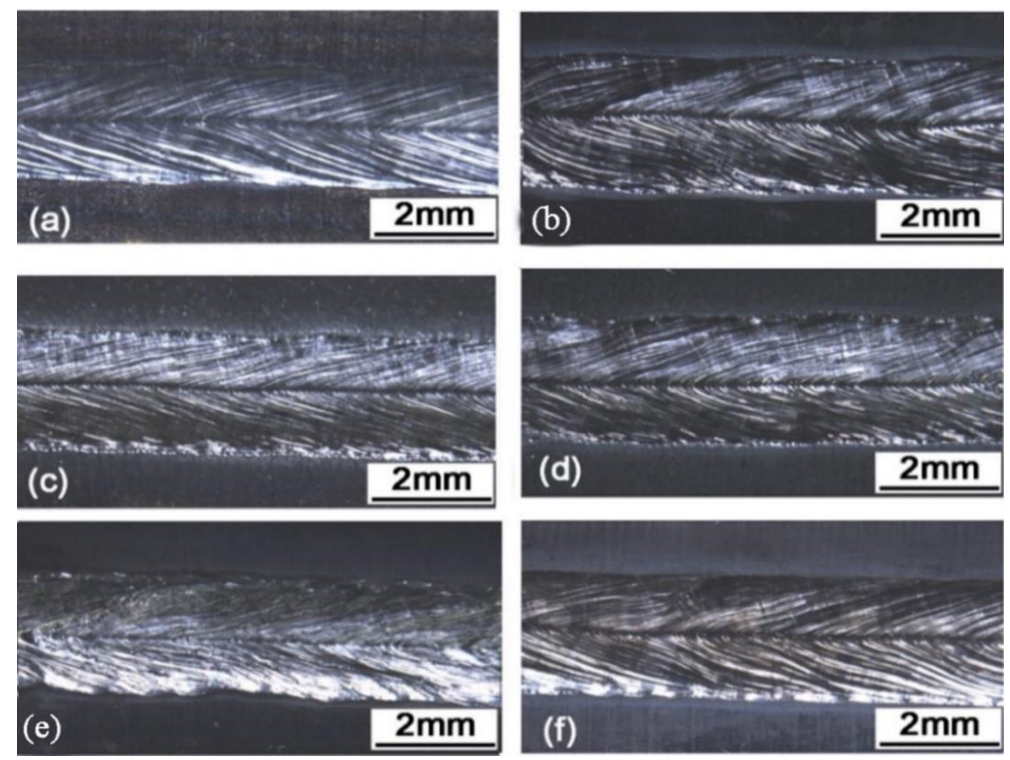

Figure 2. Effect of $R s$ on the weld appearances of the steel/Al joints produced by dual-beam laser welding with side-by-side configuration while the $d_{1}$ of $1.0 \mathrm{~mm}$, the $P_{\mathrm{L}}$ of $3000 \mathrm{~W}$, the $v$ of $33 \mathrm{~mm} / \mathrm{s}$, and the $\Delta Z$ of 0 mm were fixed: (a) 0.25 ; (b) 0.50 ; (c) 0.67 ; (d) 1.50 ; (e) 2.00 ; (f) 4.00 . 
Figure 3 shows the effect of $R s$ on the cross sections of the steel/Al joints produced by dual-beam laser welding with side-by-side configuration while the $d_{1}$ of $1.0 \mathrm{~mm}$, the $P_{\mathrm{L}}$ of $3000 \mathrm{~W}$, the $v$ of $33 \mathrm{~mm} / \mathrm{s}$, and the $\Delta Z$ of $0 \mathrm{~mm}$ were fixed. All the welds obtained at different $R s$ show a funnel weld shape, but produce obviously different P2. At the Rs of $0.25,2.00$ and 4.00, the welds completely penetrate the Al alloy side with an over-deep P2 of $1807 \mu \mathrm{m}, 1741 \mu \mathrm{m}$ and $1761 \mu \mathrm{m}$, respectively, as observed in Figure 3a,e,f. This means that the high penetration of P2 is obtained when the energy fraction of the dual beams is much more unequal, i.e., at the $R s$ of $0.25(20 / 80), 2.00(66 / 33)$ and 4.00 (80/20). However, at the $R s$ of 0.50 (33/66), 0.67 (40/60), 1.50 (60/40), the welds exhibit a relatively suitable P2 in the range of 93.2 554.2 $\mu \mathrm{m}$ due to the relatively equal energy distribution, as seen in Figure $3 \mathrm{~b}-\mathrm{d}$. As a result, the $\mathrm{P} 2$ formed in the steel/ $\mathrm{Al}$ joints is strongly affected by the Rs.
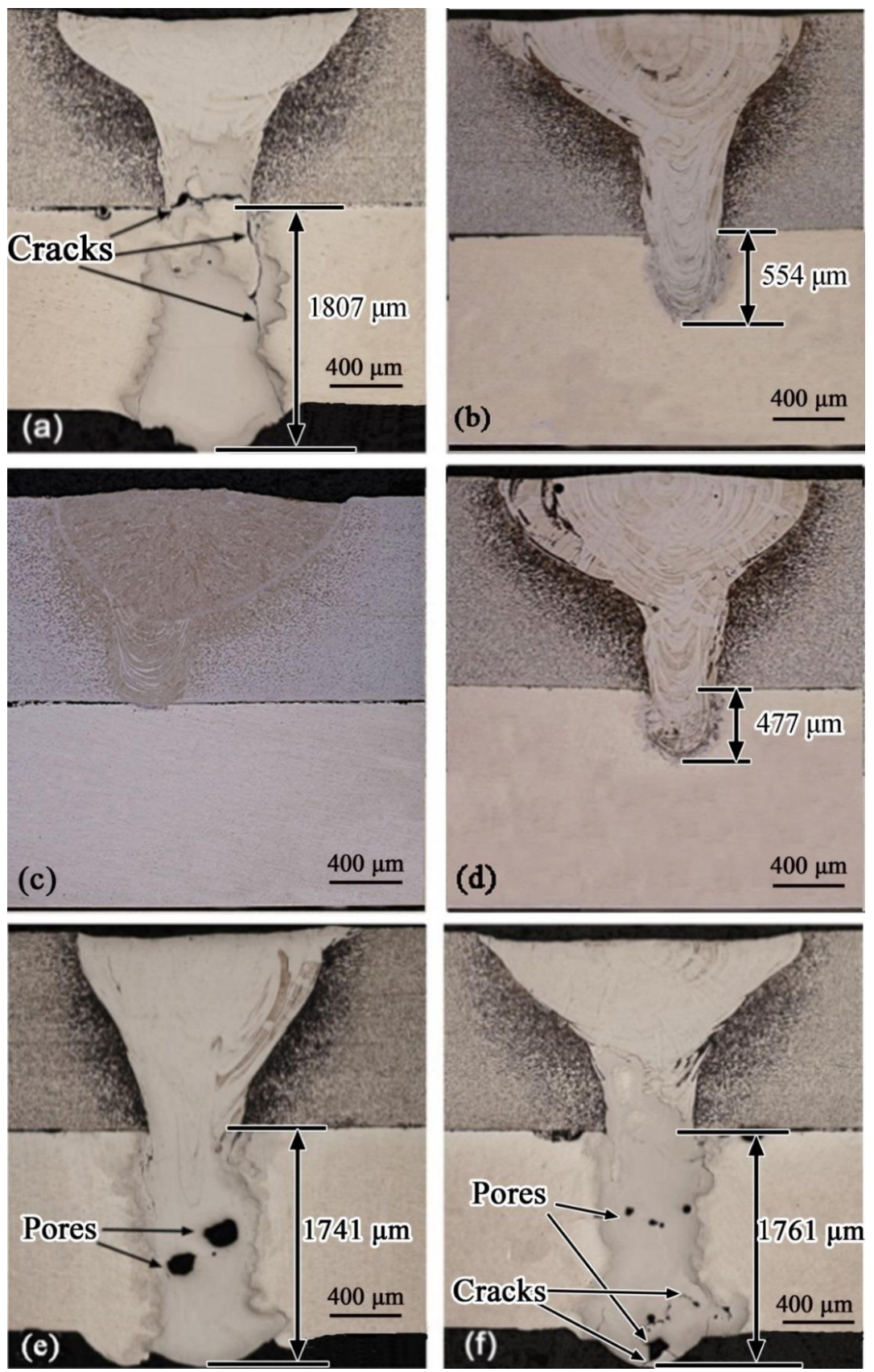

Figure 3. Effects of Rs on the cross sections of the steel/Al joints produced by dual-beam laser welding with side-by-side configuration while the $d_{1}$ of $1.0 \mathrm{~mm}$, the $P_{\mathrm{L}}$ of $3000 \mathrm{~W}$, the $v$ of $33 \mathrm{~mm} / \mathrm{s}$, and the $\Delta \mathrm{Z}$ of $0 \mathrm{~mm}$ were fixed: (a) 0.25 ; (b) 0.50; (c) 0.67 ; (d) 1.50; (e) 2.00; (f) 4.00 . 
Moreover, regarding the welding quality, it is interesting to find that increasing the P2 reduces the weld quality of the steel/Al joints. It is found that the local welding defects generated in the welds, such as pores and cracks, are also highly related to the over-deep P2 for the relatively unequal energy distribution of the Rs. No welding defects are observed in the welds with a suitable P2 at the Rs of $0.50,0.67$ and 1.50 . This means that the steel/ $\mathrm{Al}$ joints obtained at the relatively equal energy distribution exhibit no welding defects, and dividing the laser beam into unequal parts is not beneficial. Similar correlations between the energy ratio and welding defects were confirmed by Gref W et al. [29], who demonstrated that the cross sections obtained at the equal energy distribution of 50/50 show no porosity, while with a change in the distribution to $20 / 80$, for example, large process pores are visible. Consequently, it can be concluded that the good weld shape should be obtained at the relatively equal power distribution $R s$ of $0.50,0.67$ and 1.50 during side-by-side dual-beam laser welding of the steel/Al joints.

\subsubsection{Effect of the Dual-Beam Distance $\left(d_{1}\right)$}

Figure 4 shows the weld appearance of the steel/Al joints produced by dual-beam laser welding with side-by-side configuration at different $d_{1}$ varied from $0.5 \mathrm{~mm}$ to $1.5 \mathrm{~mm}$ while the $R s$ of 1.5 , the $P_{\mathrm{L}}$ of $3000 \mathrm{~W}$, the $v$ of $33 \mathrm{~mm} / \mathrm{s}$, and the $\Delta Z$ of $0 \mathrm{~mm}$ were fixed. At the small distance of $0.5 \mathrm{~mm}$, as shown in Figure 4a, the dual-beam laser welding of the steel/ Al joints provides an irregular-looking weld, but no visible welding defects of cracks and pores are observed. This is because the welding process became unstable when a single beam or a small beam distance was used [27]. Due to the small dual-beam distance, the keyhole-opening is similar to that of the single-beam welding, resulting in the instability of the keyhole [29]. With larger dual-beam distance, incasing $d_{1}$ from $0.5 \mathrm{~mm}$ to $1.5 \mathrm{~mm}$ leads to an improvement of the bead appearance, especially in view of the regularity, as shown in Figure $4 b$, c, namely, the weld appearances exhibit uniform and regular ripples without any visible cracks and pores, due to the good keyhole stability of the dual-beam laser welding with side-by-side configuration [27]. Figure $4 \mathrm{~d}$ shows two separated welds are clearly observed at the maximum $d_{1}$ of $2 \mathrm{~mm}$, because the keyhole begins to separate into two individual ones. As a result, the optimum $d_{1}$ for obtaining good bead appearance with side-by-side configuration should be in the range of $0.5 \sim 1.5 \mathrm{~mm}$.
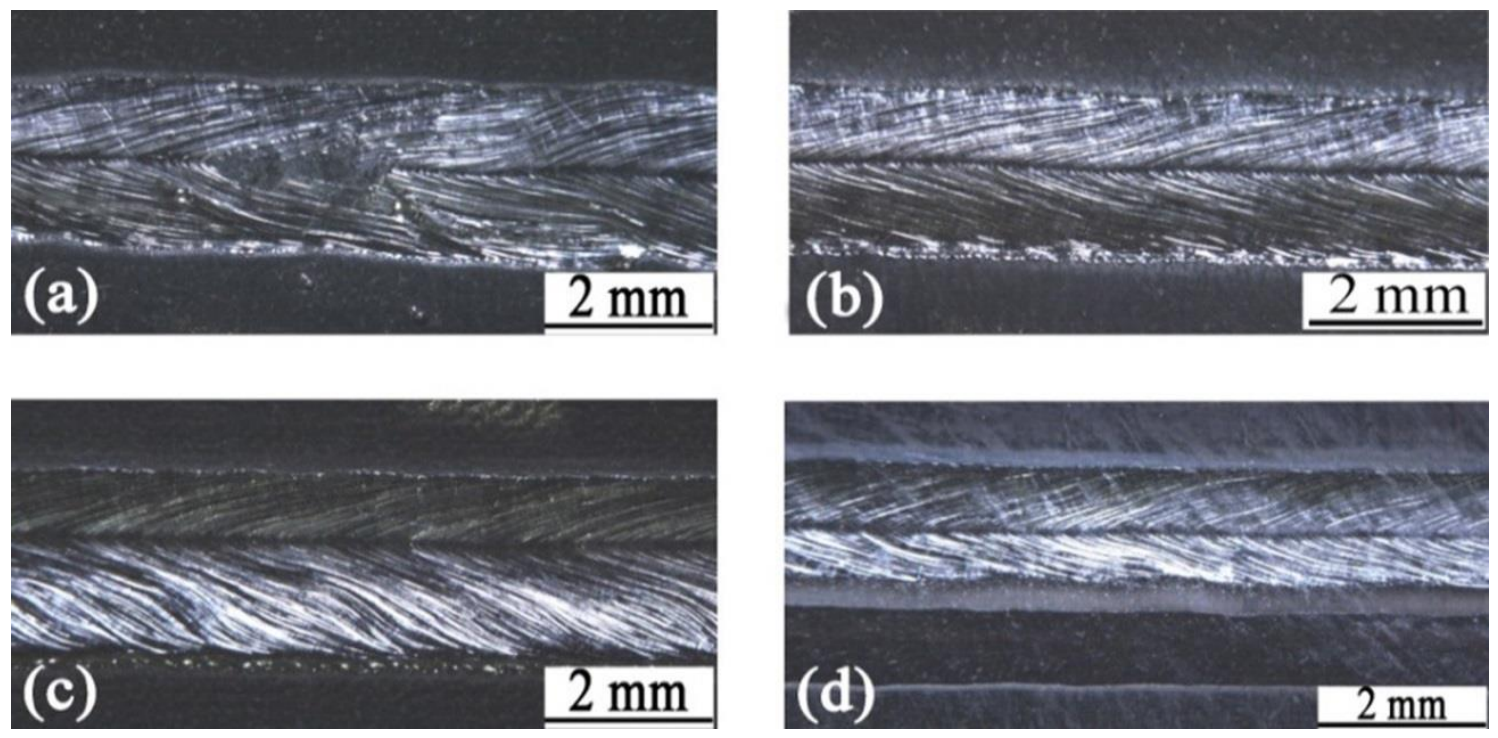

Figure 4. Effects of $d_{1}$ on the weld appearances of steel/Al joints produced by using dual-beam laser welding with side-by-side configuration while the $R s$ of 1.5 , the $P_{\mathrm{L}}$ of $3000 \mathrm{~W}$, the $v$ of $33 \mathrm{~mm} / \mathrm{s}$, and the $\Delta \mathrm{Z}$ of $0 \mathrm{~mm}$ were fixed: (a) $0.5 \mathrm{~mm}$; (b) $1.0 \mathrm{~mm}$; (c) $1.5 \mathrm{~mm}$; (d) $2.0 \mathrm{~mm}$.

Figure 5 shows the cross sections of the steel/ $\mathrm{Al}$ joints produced by dual-beam laser welding with side-by-side configuration at different $d_{1}$ varied from $0.5 \mathrm{~mm}$ to $1.5 \mathrm{~mm}$ while the $R s$ of 1.5 , the $P_{\mathrm{L}}$ 
of $3000 \mathrm{~W}$, the $v$ of $33 \mathrm{~mm} / \mathrm{s}$, and the $\Delta Z$ of $0 \mathrm{~mm}$ were fixed. As seen in Figure $5 \mathrm{a}-\mathrm{c}$, each weld of the steel/Al joints has a funnel weld shape free of pores and cracks. At the maximum $d_{1}$ of $2.0 \mathrm{~mm}$, as seen in Figure 5d, two segregated welds, including one with semicircle shape formed by conduction mode and one with funnel shape generated by a keyhole mode, are clearly observed. The two independent welds formed may be probably attributed to the formation of separated keyhole from one welding pool into two different parts [27]. In addition, the $d_{1}$ also has a significant influence on the P2. At the $d_{1}$ of $0.5 \mathrm{~mm}$, the maximum P2 of $712.9 \mu \mathrm{m}$ is achieved. Increasing $d_{1}$ from $0.5 \mathrm{~mm}$ to $1.0 \mathrm{~mm}$ decreases the P2 from $712.9 \mu \mathrm{m}$ to $94.2 \mu \mathrm{m}$. At the $d_{1}$ of $2.0 \mathrm{~mm}$, the minimum depth of P2 is zero, because of no penetration in the $\mathrm{Al}$ alloy side. As a result, the maximum P2 is achieved in the small $d_{1}$ of $0.5 \mathrm{~mm}$, and enlarging $d_{1}$ from $0.5 \mathrm{~mm}$ to $2.0 \mathrm{~mm}$ significantly decreases the P2 of the welds of steel/ $\mathrm{Al}$ joints produced by dual-beam laser welding with side-by-side configuration. This is because the interaction between the dual beams was weakening with the increase of dual-beam distances [27], and the laser welding efficiency was decreasing with larger dual-beam distance [29]. Therefore, the optimum $d_{1}$ for obtaining good weld shape is limited to $0.5 \mathrm{~mm}$ and $1.0 \mathrm{~mm}$ for side-by-side dual-beam laser welding of the steel/Al joints.
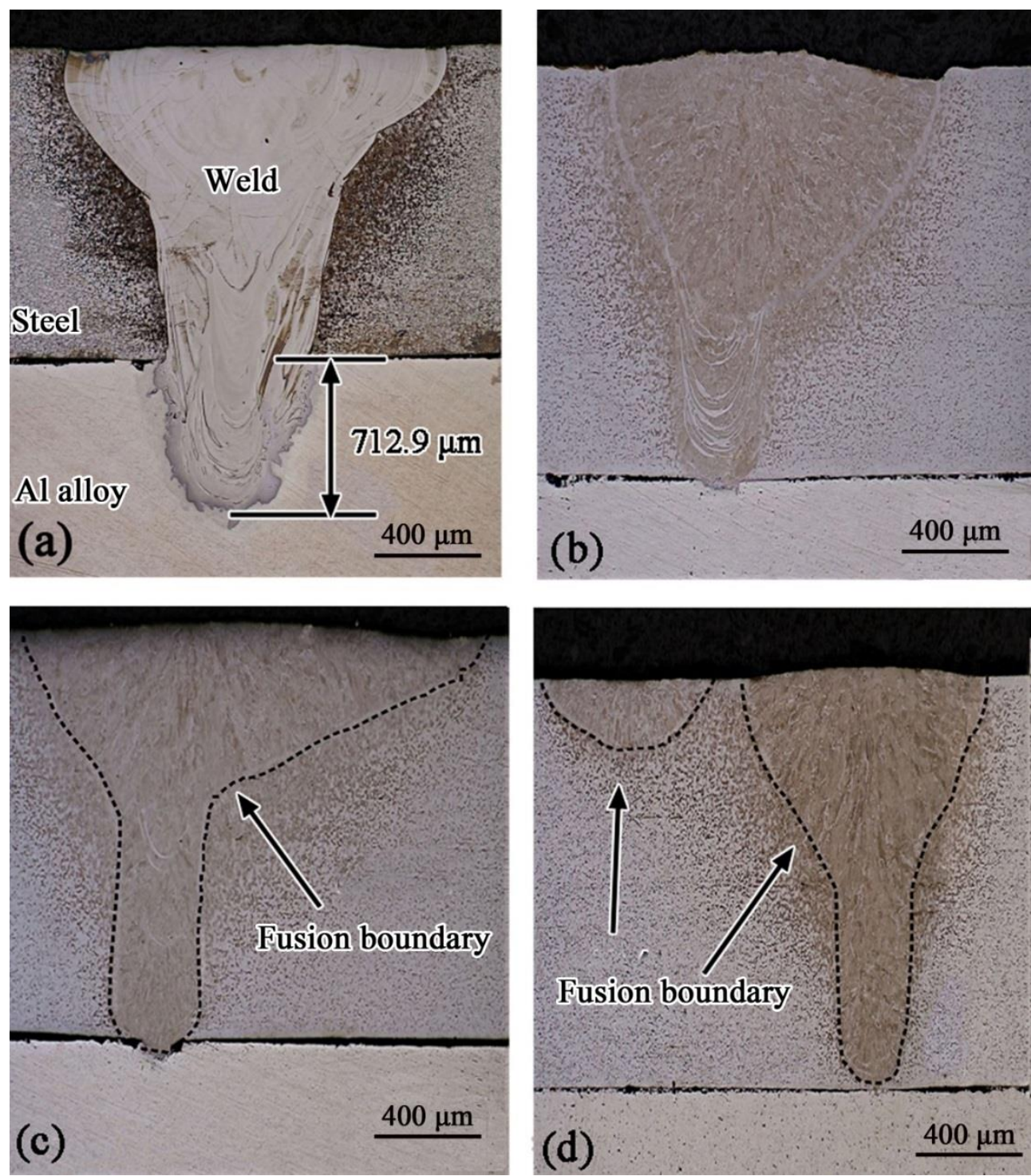

Figure 5. Effects of $d_{1}$ on cross sections of steel/Al joints produced by dual-beam laser welding with side-by-side configuration while the Rs of 1.5 , the $P_{\mathrm{L}}$ of $3000 \mathrm{~W}$, the $v$ of $33 \mathrm{~mm} / \mathrm{s}$, and the $\Delta \mathrm{Z}$ of $0 \mathrm{~mm}$ were fixed: (a) $0.5 \mathrm{~mm}$; (b) $1.0 \mathrm{~mm}$; (c) $1.5 \mathrm{~mm}$; (d) $2.0 \mathrm{~mm}$. 


\subsection{Microstructures of the Al/Weld Interface}

\subsubsection{Morphology and Thickness}

Backscatter electron (BSE) analysis was performed to exhibit the Al/weld interface microstructures of the steel/Al joints produced by dual-beam laser welding with side-by-side configuration. Figure 6a shows the typical weld shape with a P2 of $1741 \mu \mathrm{m}$. In this case, the melted steel caused by dual-beam lasers is penetrated completely into the $\mathrm{Al}$ alloy side, leading to the pores and cracks generated inside the weld. High magnification of the Al/weld interface microstructures of different Zones marked by rectangles " $b$ ", " $c$ " and " $d$ " in Figure 6a are shown in Figure 6b-d. It is found that the irregular IMC layers formed at the $\mathrm{Al} /$ weld interface display some needle-like phases and island-shape structures surrounded by lath-like layer. The formation of the island-shape structures were probably due to the stirring effect of keyhole resulting from strong convection in the welding pool [25]. This Al/weld interface characteristics of the steel/Al joints is in agreement with that of the tandem configuration [36,37].
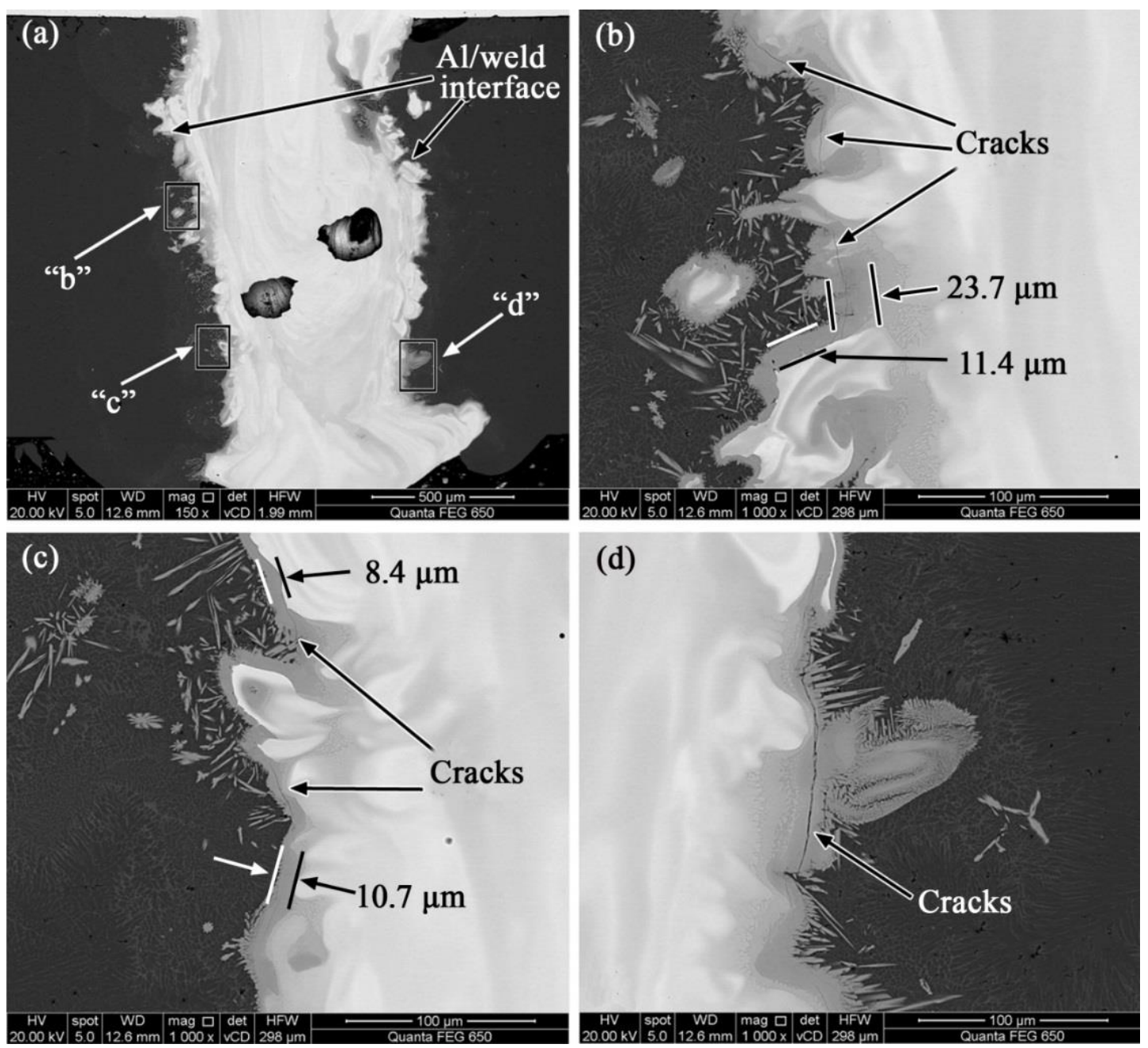

Figure 6. Backscatter electron (BSE) images of the $\mathrm{Al} /$ weld interface of the steel/Al joint having a P2 of $1741 \mu \mathrm{m}$ produced by dual-beam laser welding with side-by-side configuration: (a) Cross section of the weld and the location of rectangle of Zone " $\mathrm{b}$ "-“ $\mathrm{d}$ "; (b) Enlarged view of Zone " $\mathrm{b}$ "; (c) Enlarged view of Zone "c"; (d) Enlarged view of Zone " $d$ ".

The $\mathrm{Al} /$ weld interface microstructure in different locations consists of the island-shape structures and lath-like layer; however, the morphology and the lath-like layer thickness are different in each 
Zone. Concerning the thickness of the IMC layers, the lath-like layer thickness was utilized as an evaluation indicator due to its compact and continuous morphology for a comparative study. At the upper part of Zone " $\mathrm{b}$ ", as shown in Figure $6 \mathrm{~b}$, the lath-like layers are rather thick with a thickness of 11.4 23.7 $\mu \mathrm{m}$, and some cracks are evidently observed. At the lower part of Zone " $\mathrm{c}$ ", as presented in Figure $6 c$, the island-shape structures have relatively regular morphology surrounded by lath-like layers with thinner thickness of 8.4 10.7 $\mu \mathrm{m}$. Figure $6 \mathrm{~d}$ shows Zone " $\mathrm{d}$ " located at the other side of the $\mathrm{Al} /$ weld interface microstructures. This location has the same distance to the steel/ $\mathrm{Al}$ interface as the Zone " $c$ ". It is seen that the thickness of the lath-like layers is similar to that of Zone " $c$ ", but the needle-like phases grown from the lath-like layers are much coarser. In addition, a long crack along the lath-like layers and cross the needle-like phases is clearly observed. Therefore, the upper part primarily displays irregular island-shape structures and thicker lath-like layers, whereas the lower Zones have fine needle-like phases, thinner lath-like layers directly influenced by the relatively small heat input as a result of the far distance from the steel/Al interface [39]. The variation in the morphology and thickness with the different locations at the $\mathrm{Al} /$ weld interface microstructure can be finally attributed to the temperature gradients and cooling rates.

BSE images of the $\mathrm{Al} /$ weld interface microstructures with a suitable P2 of $477 \mu \mathrm{m}$ are presented in Figure 7. Figure 7a shows the typical weld shape formed in the $\mathrm{Al}$ alloy side free of any welding defects. The enlarged views of the $\mathrm{Al} /$ weld interface microstructures of the different Zones marked by rectangles " $b$ ", " $c$ " and " $d$ " in Figure 7a are shown in Figure $7 b-d$. At the upper part of Zone " $b$ ", a large number of needle-like phases and irregular island-shape structures surrounded by lath-like layers are found, whereas the thickness of the lath-like layers is relatively smaller in the range of $6.2 \sim 11.9 \mu \mathrm{m}$. This thickness is obviously thinner than that of the over-deep P2 shown in Figure 6. Figure 7c exhibits the $\mathrm{Al} /$ weld interface microstructures of the Zone " $\mathrm{c}$ " having the same distance to the steel/Al interface as Zone " $\mathrm{b}$ ", but locates at the other side of the $\mathrm{Al} /$ weld interface. Not only is the quantity of the needle-like phases decreased, but also the thickness of the lath-like layers is significantly decreased to $2.7 \sim 4.1 \mu \mathrm{m}$. At the bottom part of Zone "d", as shown in Figure 7d, both the thickness of the lath-like layers and the needle-like phases are also decreased significantly. Therefore, it can be concluded that the P2 has a more significant influence on the morphology and the lath-like layer thickness, and controlling the P2 is effective to inhibit the formation of IMC layers at the $\mathrm{Al} /$ weld interface. 

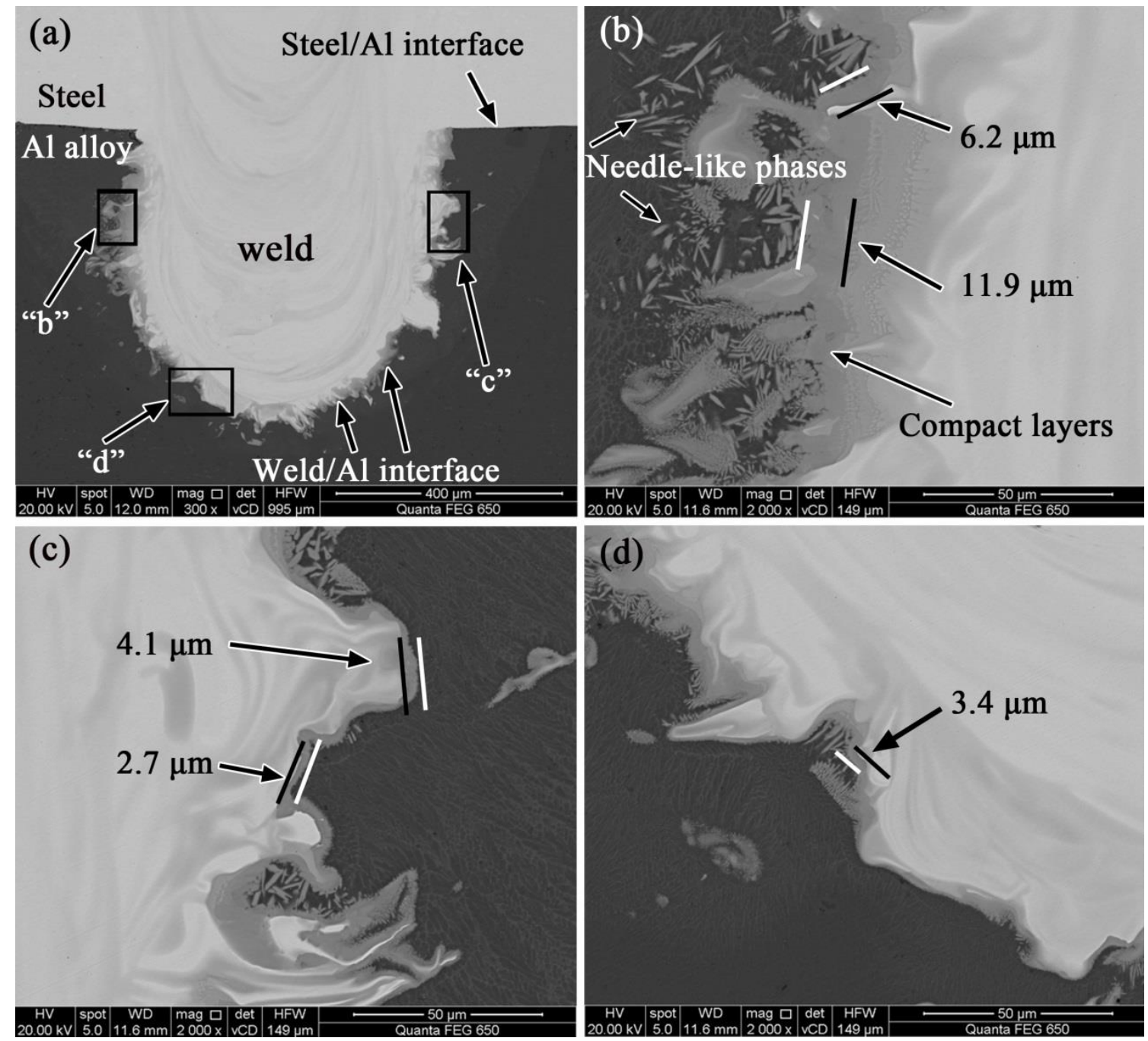

Figure 7. BSE images of the $\mathrm{Al} /$ weld interface microstructures of the steel/Al joint having a $\mathrm{P} 2$ of $477 \mu \mathrm{m}$ produced by dual-beam laser welding with side-by-side configuration: (a) Cross section of the steel/Al joint and the location of Zones "b"-“d"; (b) Enlarged view of Zone "b"; (c) Enlarged view of Zone "c"; (d) Enlarged view of Zone "d".

\subsubsection{Phase Identification}

To identify the phase type of the needle-like phases and the lath-like layers formed at the $\mathrm{Al}$ /weld interface, EBSD phase mapping was performed at the different locations marked by rectangle Zone "a-d" in Figure 8e, in which the grain color specifies the phase type distribution according to the color indicated in the phase legend for the cubic symmetry. The phase mapping of Zones " $a$ "-" $c$ " include the $\mathrm{Al}$ alloy, the $\mathrm{Al} /$ weld interface and the weld region, and Zone " $\mathrm{d}$ " is the full weld exactly right across the steel/ $\mathrm{Al}$ interface.

At the $\mathrm{Al} /$ weld interface, it is found that the blue island-shape structures are surrounded by the green lath-like layers adjacent to the blue welds, as presented in Figure 8a-c, and the red needle-like phases are dispersed in the $\mathrm{Al}$ alloy or grown from the green lath-like layers. According to the phase legend shown in the Figure 8, the green lath-like layers and the red needle-like phases are determined to be $\eta-\mathrm{Fe}_{2} \mathrm{Al}_{5}$ and $\theta-\mathrm{Fe}_{4} \mathrm{Al}_{13}$ phases. In addition, the phase mapping confirms that the variation in the location at the $\mathrm{Al} /$ weld interface results in the various morphology of the $\eta-\mathrm{Fe}_{2} \mathrm{Al}_{5}$ layers and $\theta-\mathrm{Fe}_{4} \mathrm{Al}_{13}$ phases and the different thickness of the $\eta-\mathrm{Fe}_{2} \mathrm{Al}_{5}$ layer in each zone. At the upper part of the $\mathrm{Al}$ /weld interface of Zone "a", the $\eta-\mathrm{Fe}_{2} \mathrm{Al}_{5}$ layers are rather thick, and a large number of the $\theta-\mathrm{Fe}_{4} \mathrm{Al}_{13}$ phases are confirmed. At the lower part of Zone " $\mathrm{b}$ ", the weld region is found to be 
dominated by $\alpha$-Fe phase with curved columnar grains and the less $\theta-\mathrm{Fe}_{4} \mathrm{Al}_{13}$ phases and the thinner $\eta-\mathrm{Fe}_{2} \mathrm{Al}_{5}$ layers formed at the $\mathrm{Al} /$ weld interface have been proved. In particular, it is noted that some very fine $\theta-\mathrm{Fe}_{4} \mathrm{Al}_{13}$ and $\eta-\mathrm{Fe}_{2} \mathrm{Al}_{5}$ phases distributed along $\alpha$-Fe grain boundaries are observed inside the weld region, which is proved by further examining the Kikuchi diffraction patterns and the lattice constants. Figure $8 \mathrm{c}$ proves the highly reduced quantity of the $\theta-\mathrm{Fe}_{4} \mathrm{Al}_{13}$ phases and the $\eta-\mathrm{Fe}_{2} \mathrm{Al}_{5}$ layer thickness are generated at the $\mathrm{Al} /$ weld interface at the bottom part of Zone " $\mathrm{c}$ ". In addition, the fine $\theta-\mathrm{Fe}_{4} \mathrm{Al}_{13}$ and $\mathrm{Fe}_{2} \mathrm{Al}_{5}$ phases are confirmed to generate along $\alpha-\mathrm{Fe}$ grain boundaries inside the weld zone close to the $\mathrm{Al} /$ weld interface. Figure $8 \mathrm{~d}$ presents the phase distribution of the weld Zone " $\mathrm{d}$ " across the steel/Al interface, exhibiting that the very fine $\theta-\mathrm{Fe}_{4} \mathrm{Al}_{13}$ and $\eta-\mathrm{Fe}_{2} \mathrm{Al}_{5}$ phases are formed along $\alpha$-Fe grain boundaries inside the weld zone. With these EBSD observations, it can be concluded that the $\theta-\mathrm{Fe}_{4} \mathrm{Al}_{13}$ and $\eta-\mathrm{Fe}_{2} \mathrm{Al}_{5}$ phase are formed at the $\mathrm{Al} /$ weld interface, and the very fine $\theta-\mathrm{Fe}_{4} \mathrm{Al}_{13}$ and $\eta-\mathrm{Fe}_{2} \mathrm{Al}_{5}$ phases are generated along $\alpha$-Fe grain boundary inside the weld zone of the steel/Al joints.

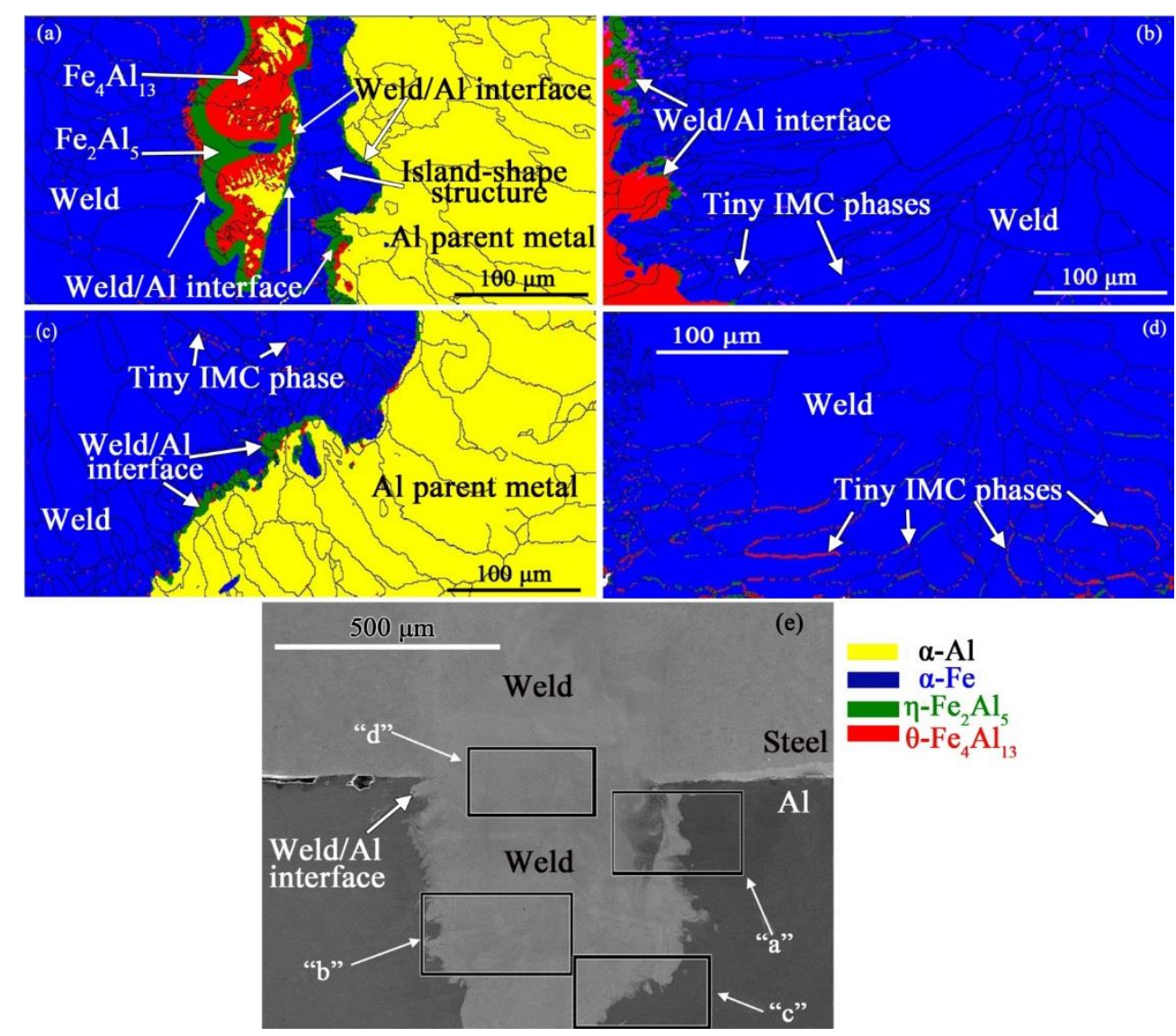

Figure 8. EBSD phase mapping images of the different zones in the steel/Al joints produced by dual-beam laser welding with side-by-side configuration: (a) Zone "a" marked in (e); (b) Zone " $\mathrm{b}$ " marked in (e); (c) Zone "c" marked in (e); (d) Zone " $\mathrm{d}$ " marked in (e); (e) Cross section of steel/ Al joint and the locations of Zones " $a-d$ ".

This present study indicates that the $\theta-\mathrm{Fe}_{4} \mathrm{Al}_{13}$ and $\eta-\mathrm{Fe}_{2} \mathrm{Al}_{5}$ phases are formed at the $\mathrm{Al} /$ weld interface, which is in good agreement with the previous studies $[19,36,40]$. However, the formation of the fine $\theta-\mathrm{Fe}_{4} \mathrm{Al}_{13}$ and $\mathrm{Fe}_{2} \mathrm{Al}_{5}$ phases formed along $\alpha$-Fe grain boundary has not been reported. The reasons for the fine IMC phases maybe partly correlated to the high Al content at the upper part of the weld zone due to the over-deep P2 in the Al alloy side [24]. In addition, the high vacancies are concentrated along the c-axis of the orthorhombic structure of the $\eta-\mathrm{Fe}_{2} \mathrm{Al}_{5}$ phase, and thus high content $\mathrm{Al}$ atoms can diffuse rapidly in this direction and even travel across the formed $\eta-\mathrm{Fe}_{2} \mathrm{Al}_{5}$ 
phase [41], which leads to the $\theta-\mathrm{Fe}_{4} \mathrm{Al}_{13}$ phases formed in both sides of $\eta-\mathrm{Fe}_{2} \mathrm{Al}_{5}$ layer. When $\mathrm{Al}$ atoms cross $\eta-\mathrm{Fe}_{2} \mathrm{Al}_{5}$ phase, they continue to migrate along $\alpha$-Fe grain boundaries in as much as grain boundary diffusion coefficient is much higher than bulk diffusion coefficient [42]. Al atoms diffuse along $\alpha$-Fe grain boundary and react with Fe atoms existing in the $\alpha$-Fe grain boundaries to form $\eta-\mathrm{Fe}_{2} \mathrm{Al}_{5}$ and $\theta-\mathrm{Fe}_{4} \mathrm{Al}_{13}$ phases finally. This may explain why the fine $\theta-\mathrm{Fe}_{4} \mathrm{Al}_{13}$ and $\eta-\mathrm{Fe}_{2} \mathrm{Al}_{5}$ phases are formed along $\alpha$-Fe grain boundary inside the weld zones.

\subsubsection{Grain Shape and Grain Size}

The microstructures of the $\mathrm{Al} /$ weld interface and the weld for the steel/ $\mathrm{Al}$ joints are also depicted by EBSD orientation image mapping (OIM), where the grain color specifies the orientation according to the coloring indicated in the orientation legend for the cubic symmetry. Hence, the grain shape was easily detected as the grain boundaries with angle misorientations larger than $5^{\circ}$ were displayed, and the grain size was statistically estimated by means of EBSD software. Figure 9 displays the OIM of different locations at the $\mathrm{Al}$ /weld interface marked by rectangle Zones "a" -"c" in Figure 8e. It is found that the weld zone concludes some equiaxed structures and predominantly columnar grains. The Al base metal exhibits the much coarser columnar structures with an average grain size of $71.6 \mu \mathrm{m}$, which is noticeably coarser than those of the IMC grains formed at the $\mathrm{Al} /$ weld interface.

Considering the IMC grains at the $\mathrm{Al}$ / weld interface, the variation in locations causes the different size of the $\eta-\mathrm{Fe}_{2} \mathrm{Al}_{5}$ and the $\theta-\mathrm{Fe}_{4} \mathrm{Al}_{13}$ grains. At the upper part of Zone "a", the $\eta-\mathrm{Fe}_{2} \mathrm{Al}_{5}$ grains are in shape of the continuous layer with an average grain size of $41.2 \mu \mathrm{m}$, and the needle-like $\theta-\mathrm{Fe}_{4} \mathrm{Al}_{13}$ grains adjacent to the $\eta-\mathrm{Fe}_{2} \mathrm{Al}_{5}$ layers are in an average size of $6.1 \mu \mathrm{m}$. At the lower part of Zone " $\mathrm{b}$ ", the $\eta-\mathrm{Fe}_{2} \mathrm{Al}_{5}$ and the $\theta-\mathrm{Fe}_{4} \mathrm{Al}_{13}$ grains change into finer equiaxed morphology with a size of 3.6 24.3 $\mu \mathrm{m}$. At the bottom part of Zone "c", the $\theta-\mathrm{Fe}_{4} \mathrm{Al}_{13}$ and the $\eta-\mathrm{Fe}_{2} \mathrm{Al}_{5}$ grains are equiaxed with the smallest size of $2.14 \mu \mathrm{m}$ and $5.6 \mu \mathrm{m}$. As a result, the finest $\theta-\mathrm{Fe}_{4} \mathrm{Al}_{13}$ and $\eta-\mathrm{Fe}_{2} \mathrm{Al}_{5}$ grains has been obtained at the bottom part of the $\mathrm{Al} /$ weld interface, which undergoes higher cooling rates compared to the upper part. The noticeable decrease in grain size of the $\theta-\mathrm{Fe}_{4} \mathrm{Al}_{13}$ and $\eta-\mathrm{Fe}_{2} \mathrm{Al}_{5}$ grains with increasing the distance to the steel/ $\mathrm{Al}$ interface is probably attributable to the location-variable cooling rate experienced at the $\mathrm{Al} /$ weld interface. A relatively slower velocity of solidification in the upper part is due to a substantial heat for a longer period of time, whereas the bottom part experiences less heat input owing to the greater distance from the steel/ $\mathrm{Al}$ interface [24,36]. Moreover, the fine $\theta-\mathrm{Fe}_{4} \mathrm{Al}_{13}$ and $\eta-\mathrm{Fe}_{2} \mathrm{Al}_{5}$ grains formed inside the welds have an average size of $2.4 \sim 3.7 \mu \mathrm{m}$ and 2.1 3.6 $\mu \mathrm{m}$. Therefore, the IMC grains formed whether in the $\mathrm{Al} /$ weld interface or in the welds produced by dual-beam laser welding with side-by-side configuration are much finer than those of the welds and the Al base metal, which may be beneficial to improve the tensile resistance of the steel/ Al joints. Now, it is a pity that the relationships between fine IMC microstructure and mechanical properties are not very clear. This observation and other aspects of the underlying relationships will be investigated further. 


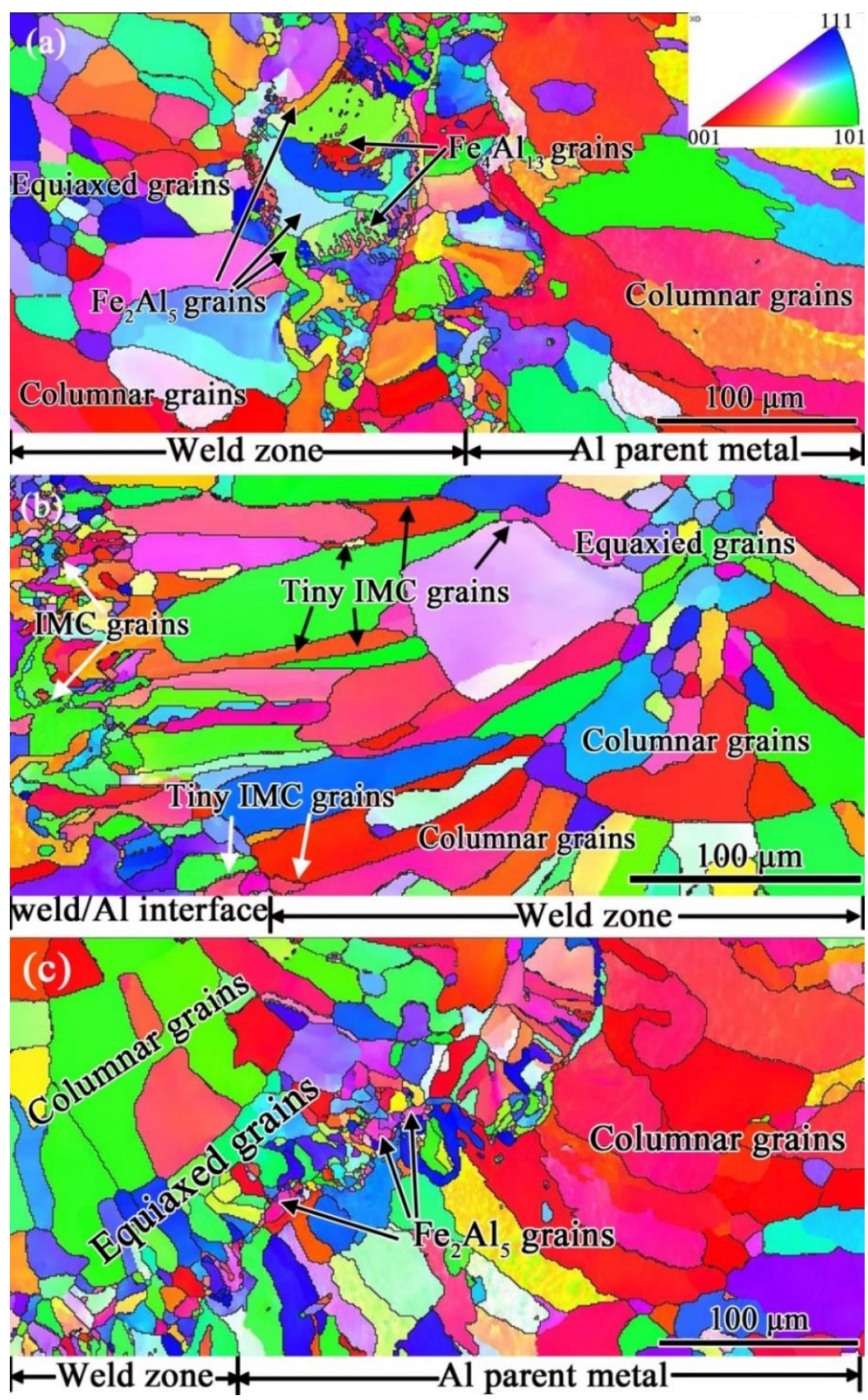

Figure 9. OIM of different zones of the steel/Al joints produced by dual-beam laser welding with side-by-side configuration: (a) Zone "a" marked in Figure 8e; (b) Zone "b" marked in Figure 8e; (c) Zone " $c$ " marked in Figure 8e.

\subsection{Tensile Resistance of the Steel/Al Joints}

Figure 10a shows the tensile resistance of the steel/ $\mathrm{Al}$ joints produced by dual-beam laser welding with side-by-side configuration at different $R s$ varied from 0.25 to 4.00 . At the $R s$ of 0.25 and 4.00, the tensile resistance of the steel/ $\mathrm{Al}$ joints is $48.4 \mathrm{~N} / \mathrm{mm}$, and $52.5 \mathrm{~N} / \mathrm{mm}$, which is rather low, probably due to the cracks and pores formed inside the weld zone associated with the over-deep P2 (Figure 3a,f). At the $R s$ of 0.50 and 1.50, the tensile resistance of the steel/ $\mathrm{Al}$ joints is greatly increased to $84.8 \mathrm{~N} / \mathrm{mm}$ and $109.2 \mathrm{~N} / \mathrm{mm}$, probably due to the suitable P2 (Figure 3b,d). Figure 10b shows the tensile resistance of the steel/Al joints with different $d_{1}$ varied from $0.5 \mathrm{~mm}$ to $2.00 \mathrm{~mm}$. At the $d_{1}$ of $2.00 \mathrm{~mm}$, tensile test of the steel/Al joints was not tested because no welded joints were obtained. It is found that increasing $d_{1}$ from $0.5 \mathrm{~mm}$ to $1.5 \mathrm{~mm}$ decreases the tensile resistance of the steel/ $\mathrm{Al}$ joints from $100.2 \mathrm{~N} / \mathrm{mm}$ to 
$43.3 \mathrm{~N} / \mathrm{mm}$. Thus, the maximum tensile resistance of $100.2 \mathrm{~N} / \mathrm{mm}$ has been obtained at the $\mathrm{d} 1$ of $0.5 \mathrm{~mm}$ due to the optimal P2 (Figure 5a), and the lowest tensile resistance of $43.3 \mathrm{~N} / \mathrm{mm}$ is obtained at the $d_{1}$ of $1.5 \mathrm{~mm}$ due to the insufficient P2 (Figure $5 \mathrm{c}$ ). This indicates that the linear relationship between the $\mathrm{P} 2$ and the tensile resistance of the steel/ $\mathrm{Al}$ joints. From these results, it is concluded that there is a matching relationship between the P2 and the tensile resistance of steel/Al joints, and the maximum tensile resistance of the steel/ $\mathrm{Al}$ joints is obtained at the $R s$ of 1.50 produced by dual-beam laser welding with side-by-side configuration.
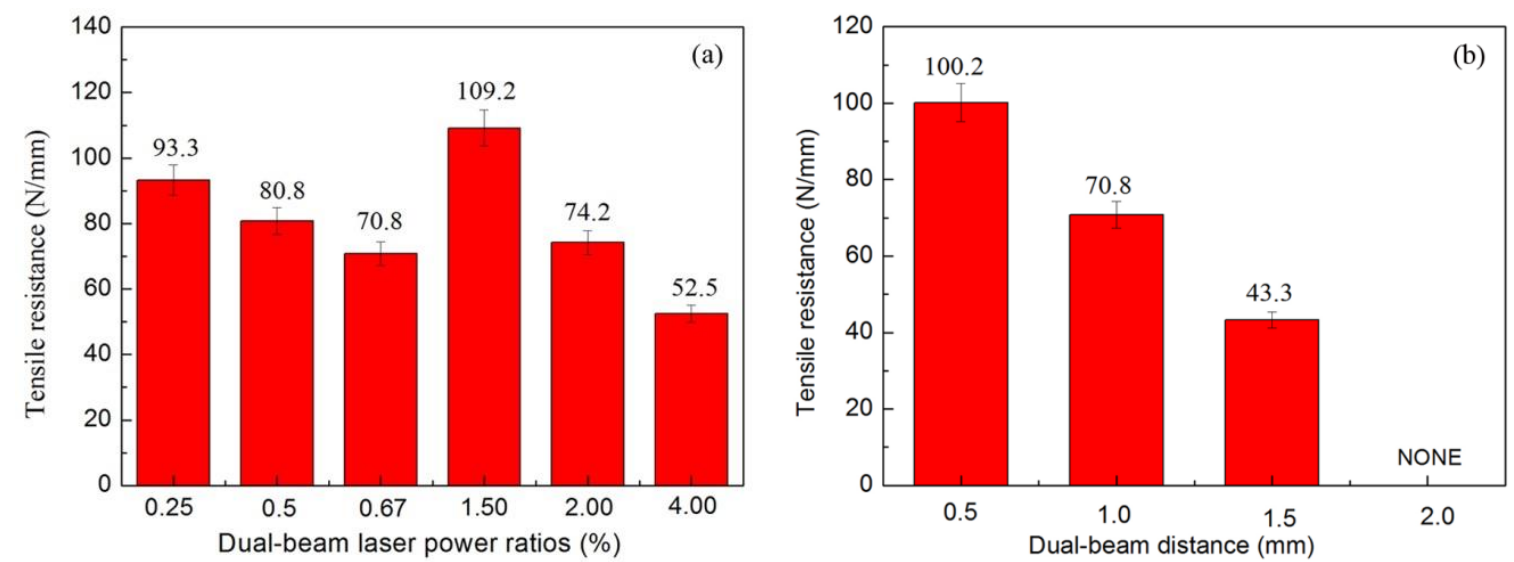

Figure 10. Effect of processing parameters on tensile resistance of the steel/Al joints produced by dual-beam laser welding with side-by-side configuration: (a) $R s$ varied from 0.25 to 4.00 ; (b) $d_{1}$ varied from $0.5 \mathrm{~mm}$ to $2.0 \mathrm{~mm}$.

After the tensile test, all the steel/ $\mathrm{Al}$ joints have been fractured at the $\mathrm{Al} /$ weld interface due to the brittleness of the IMC layers at the $\mathrm{Al} /$ weld interface. Figure 11 shows a typical strain-stress curve of the steel/Al joints obtained by three dual-beam distances with very small strain of the steel/Al joints, indicating a brittle fracture characteristic.

During the tensile test, the crack initiates from the steel/Al interface because of the higher stress concentration, and grows along the steel/Al interface to the weld border. Two different fracture propagation paths are observed depending on the P2. The first one occurred at the steel/Al joint with an over-deep P2 of $1741 \mu \mathrm{m}$, is shown in Figure 12. Figure 12a shows that the crack propagates along the $\mathrm{Al} /$ weld interface and in the weld zone above the steel/Al interface, indicating that both the $\mathrm{Al} /$ weld interface regions and the weld zone above the steel/ $\mathrm{Al}$ interface are the weakening zones of the steel/Al joints. The weak weld zone above the steel/ $\mathrm{Al}$ interface is probably due to the higher Al content resulted from the over-deep P2 [36], whereas the fractured Al/weld interface is associated with the high brittleness of the $\eta-\mathrm{Fe}_{2} \mathrm{Al}_{5}$ and $\theta-\mathrm{Fe}_{4} \mathrm{Al}_{13}$ phases. High magnification of the fracture path morphology of the Al/weld interface is shown in Figure 12b. It is indicated that remarkable different fracture morphologies are observed with various locations marked as rectangle " $\mathrm{c}$ " and " $\mathrm{d}$ " in Figure 12b along Al/weld interface. At Zone " $c$ " near the steel/ $\mathrm{Al}$ interface shown in Figure 12c, some cracks are observed across the needle-like $\theta-\mathrm{Fe}_{4} \mathrm{Al}_{13}$ phases. The fracture is occurred in the $\eta-\mathrm{Fe}_{2} \mathrm{Al}_{5}$ layer close to the weld, which results in lower tensile resistance of the steel/Al joints [13]. In this case, the crack path is relatively straight, which reveals the crack growth resistance in the $\eta-\mathrm{Fe}_{2} \mathrm{Al}_{5}$ layer is low. The $\eta-\mathrm{Fe}_{2} \mathrm{Al}_{5}$ layer at the $\mathrm{Al}$ /weld interfaces becoming a preferential cracking path are due to the cracks existed before tensile testing [24]. At Zone " $\mathrm{d}$ " far from the steel/Al interface, as shown in Figure 12d, only large needle-like $\theta-\mathrm{Fe}_{4} \mathrm{Al}_{13}$ phases are formed at the $\mathrm{Al} /$ weld interface free of cracks. At this location, a fairly jagged looking fracture path is observed and the fracture takes place along the $\mathrm{Al}$ /weld interface between the $\mathrm{Al}$ alloy and the $\eta-\mathrm{Fe}_{2} \mathrm{Al}_{5}$ layer, which results in higher joining strength [13]. Therefore, the fracture path varied with the morphology and the thickness of the IMC layer result in the tensile resistance variation with the location in the $\mathrm{Al} /$ weld interface. The factographic surface of the weld / Al interface marked by Zone " $f$ " (Figure 12e) reveals a typical 
cleavage fracture mode, as shown in Figure 12f, with river pattern strips of particular orientation on the fracture surface. The $\eta-\mathrm{Fe}_{2} \mathrm{Al}_{5}$ layer was the most brittle region having the weakest bonding strength at the weld/Al interface of the steel/ $\mathrm{Al}$ joints.

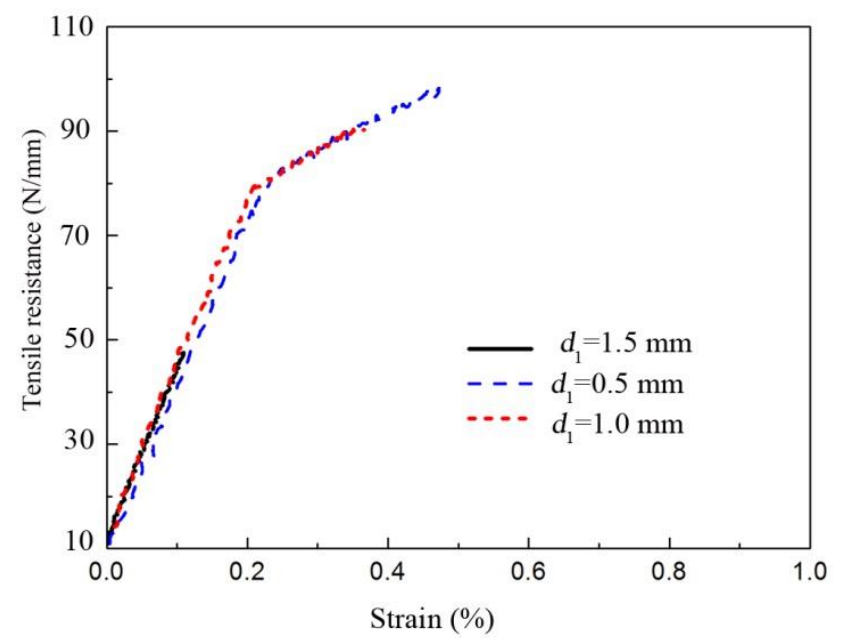

Figure 11. Stress-strain curves of the steel/Al joints obtained by dual-beam laser welding with side-by-side configuration for three different $d_{1}$.

For the second one, as shown in Figure 13a, the macrofracture profile of the steel/Al joints with an optimized P2 of $477 \mu \mathrm{m}$ is obviously different from that of the over-deep P2. It is from the BSE images shown in Figure 13a found that the crack propagates in $\eta-\mathrm{Fe}_{2} \mathrm{Al}_{5}$ layer along $\mathrm{Al}$ /weld interface, and grows into the $\mathrm{Al}$ alloys at the bottom of the weld, and then connects to the fracture crack resulting in the final tearing of the steel/Al joint. This means that the weaken zones of the steel/Al joints turns into $\mathrm{Al}$ /weld interface regions and the $\mathrm{Al}$ alloy at the bottom of the weld, which induces the tensile resistance of the $\mathrm{Al}$ alloy at the bottom of the weld lower than the tensile strength of the weld zone in the upper part of the steel/ $\mathrm{Al}$ joint. The fracture surfaces of Zones " $\mathrm{b}$ " and " $c$ " marked by rectangle in Figure 13a are shown in Figure 13c,d, respectively. The fracture surface of the Zone " $b$ " was full of the tearing edges and river patterns, whereas some ductile dimples were clearly observed at the fracture surface of Zone " $\mathrm{c}$ " indicating some plastic deformation occurred. Thus, the fracture mode of the steel/Al joint with the optimized depth of $\mathrm{P} 2$ was a mixed failure, which significantly enhanced its tensile resistance of the steel/Al joint. Similar fracture behavior of the steel/Al joints was reported by Chen et al. [17] during laser penetration welding an overlap steel-on-aluminum joint with/without Ni-Foil. They have demonstrated that the relatively high tensile strength was achieved when the joints exhibited a characteristic ductile fracture occurred in the parent metal or seam, whereas the tensile strength was relatively low with a brittle fracture characteristic when the joints fractured only along IMC layers in the interface. This can explain why the second fracture propagation paths occurred in the steel/Al joint with an optimized P2 exhibit a relatively high tensile resistance. 


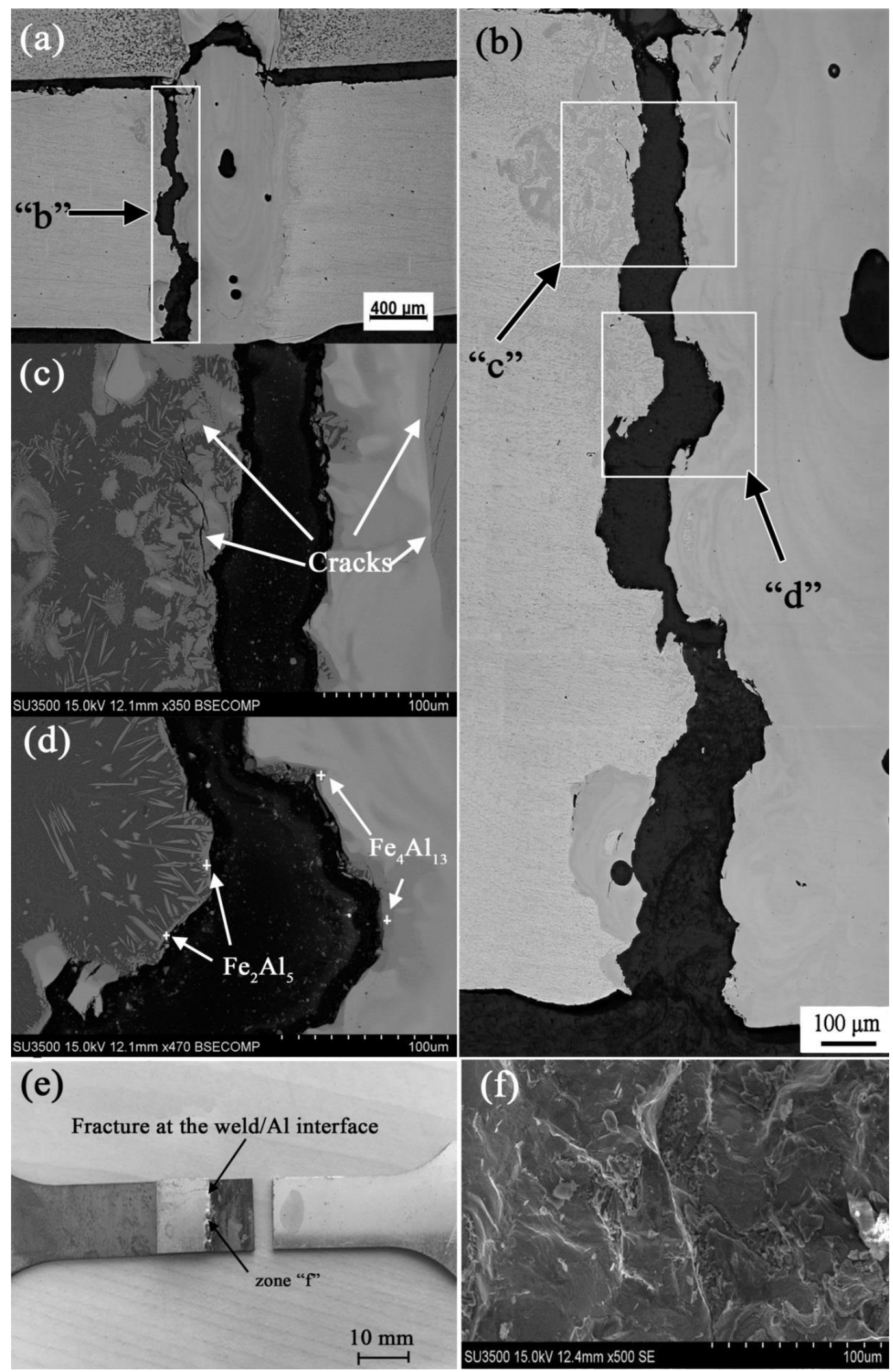

Figure 12. Fracture path morphology of steel/Al joints having an over-deep P2 of $1741 \mu \mathrm{m}$ produced by dual-beam laser welding with side-by-side configuration arrangement: (a) Macroscopic fractured steel/Al joint; (b) High magnification of fracture path and locations of Zones " $c$ " and " $d$ "; (c) BSE image of enlarged view of Zone "c"; (d) BSE image of enlarged view of Zone "d"; (e) Macroscopic fractured steel/ Al joints; (f) Fracture surface of Zone " $\mathrm{f}$ " in (e). 

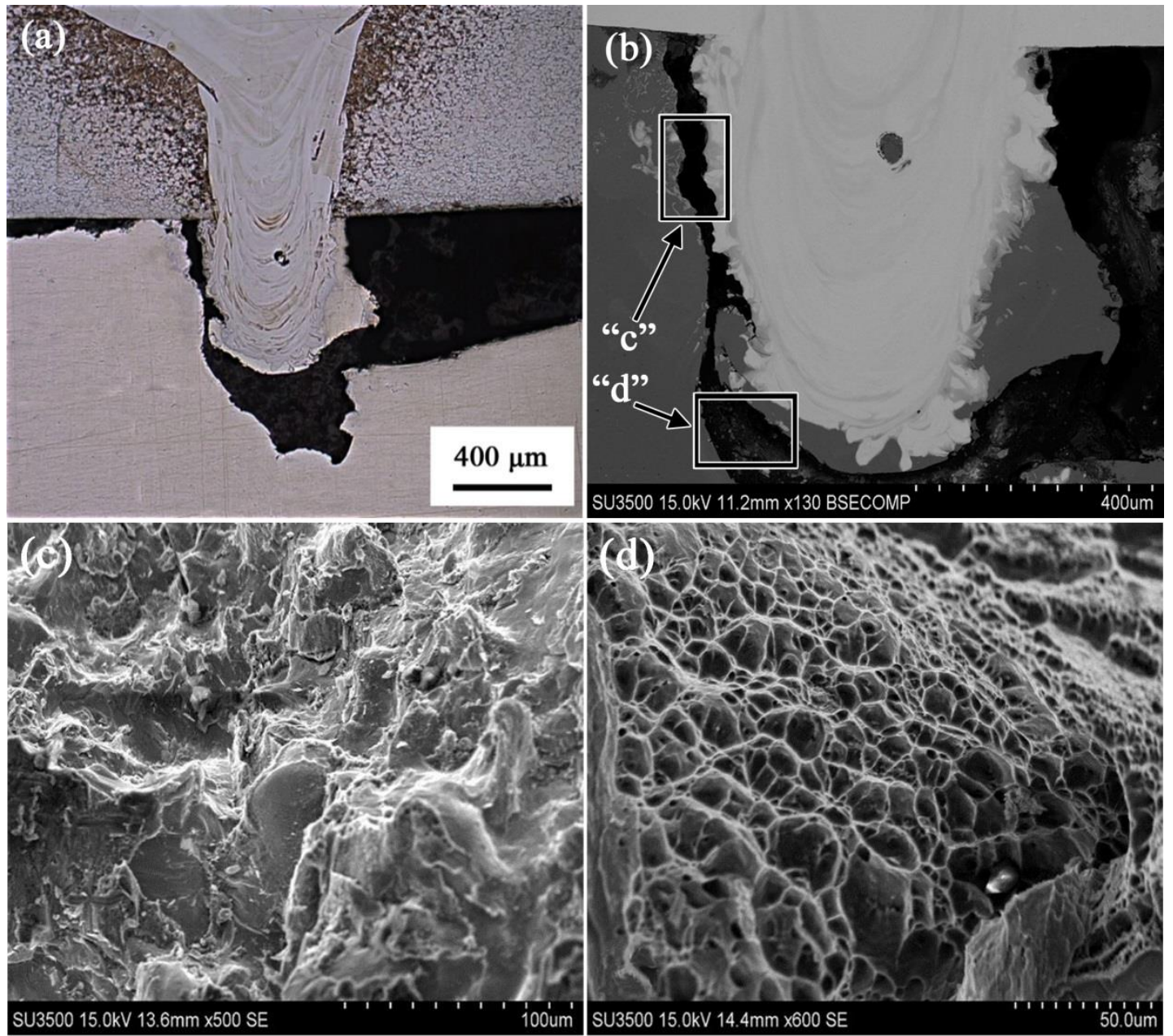

Figure 13. Fracture path morphology of steel/Al joints with an optimum P2 of $477 \mu \mathrm{m}$ produced by dual-beam laser welding with side-by-side configuration: (a) Macroscopic fractured steel/Al joint; (b) BSE image of enlarged view of fracture path; (c) SEM image of fracture surface of Zone "c"; (d) SEM image of fracture surface of Zone " $\mathrm{d}$ ".

\section{Conclusions}

A Q235 low carbon steel and 6061Al alloys of $1.5 \mathrm{~mm}$ thickness were welded by dual-beam fiber laser welding with side-by-side configuration. From the present results, the following major conclusions were reached:

(1) Soundly welded steel/Al lapped joints free of welding defects have been successfully achieved by using dual-beam laser welding with side-by-side configuration. The processing parameters of $R s$ and $d_{1}$ have a great influence on the weld appearance, the P2 and the welding defects. The good weld shape should be obtained at the relatively equal $R s$ of $0.50,0.67$ and 1.50 during side-by-side dual-beam laser welding of the steel/ $\mathrm{Al}$ joints. The optimum $d_{1}$ for obtaining good weld shape is limited to $0.5 \mathrm{~mm}$ and $1.0 \mathrm{~mm}$ for side-by-side dual-beam laser welding of the steel/Al joints.

(2) The $\mathrm{Al} /$ weld interface microstructure in different locations consists of the island-shape structures and lath-like layer; however, the morphology and the lath-like layer thickness are different in each zone. The P2 has a significant influence on the morphology and the lath-like layer thickness, and controlling the P2 is effective to inhibit the formation of IMC layers at the Al/weld interface.

(3) EBSD phase mapping proves that the microstructures at the $\mathrm{Al} /$ weld interface are composed of the $\eta-\mathrm{Fe}_{2} \mathrm{Al}_{5}$ layers and the $\theta-\mathrm{Fe}_{4} \mathrm{Al}_{13}$ phases, and very fine $\theta-\mathrm{Fe}_{4} \mathrm{Al}_{13}$ and $\eta-\mathrm{Fe}_{2} \mathrm{Al}_{5}$ phases are 
formed along $\alpha$-Fe grain boundary inside the weld of the steel/ $\mathrm{Al}$ joints. The $\eta-\mathrm{Fe}_{2} \mathrm{Al}_{5}$ layers and the needle-like $\theta-\mathrm{Fe}_{4} \mathrm{Al}_{13}$ grains formed at the $\mathrm{Al} /$ weld interface are finer than those of the weld and the $\mathrm{Al}$ alloy.

(4) There is a matching relationship between the P2 and the tensile resistance of steel/ $\mathrm{Al}$ joints produced by dual-beam laser welding with side-by-side configuration, and the maximum tensile resistance of the steel/ $\mathrm{Al}$ joints is obtained at the $R$ s of 1.50 during dual-beam laser welding with side-by-side configuration.

(5) Two different fracture propagation paths are found depending on the P2. The fracture profile of the steel/Al joints with an optimized P2 exhibits a ductile fracture occurring in the parent metal or seam, resulting in a relatively high tensile resistance of the steel/ $\mathrm{Al}$ joints.

Author Contributions: L.C. and D.H. conceived and designed the experiments; H.C. and B.C. performed the experiments; H.C. analyzed the data; L.C. wrote the paper. D.H. did the literature searching and reviewed the manuscript.

Funding: This research was funded by [the National Natural Science Foundation of China] grant number [51475006] and [the Key Program of Science and Technology Projects of Beijing Municipal Commission of Education] grant number [KZ201610005004].

Acknowledgments: Li Cui truly appreciates Li Chen (AVIC Manufacturing Technology Institute, China) for giving important insights and sharing fruitful discussion.

Conflicts of Interest: The authors declare no conflicts of interest.

\section{References}

1. Sun, Z.; Ion, J.C. Review laser welding of dissimilar metal combinations. J. Mater. Sci. 1995, 30, 4205-4214. [CrossRef]

2. Shah, L.H.; Ishak, M. Review of research progress on aluminum-steel dissimilar welding. Mater. Manuf. Process. 2014, 29, 928-933. [CrossRef]

3. Shao, L.; Shi, Y.; Huang, J.K.; Wu, S.J. Effect of joining parameters on microstructure of dissimilar metal joints between aluminum and galvanized steel. Mater. Des. 2015, 66, 453-458. [CrossRef]

4. Song, J.L.; Lin, S.B.; Yang, C.L.; Ma, G.C.; Liu, H. Spreading behavior and microstructure characteristics of dissimilar metals TIG welding-brazing of aluminum alloy to stainless steel. Mater. Sci. Eng. A 2009, 509, 31-40. [CrossRef]

5. Katayama, S. Laser welding of aluminium alloys and dissimilar metals. Weld Int. 2004, 18, 618-625. [CrossRef]

6. Meco, S.; Pardal, G.; Ganguly, S.; Williams, S.; Mcpherson, N. Application of laser in seam welding of dissimilar steel to aluminium joints for thick structural components. Opt. Laser Eng. 2015, 67, 22-30. [CrossRef]

7. Corigliano, P.; Crupi, V.; Guglielmino, E.; Sili, A.M. Full-field analysis of Al/Fe explosive welded joints for shipbuilding applications. Mar. Struct. 2018, 57, 207-218. [CrossRef]

8. Corigliano, P.; Crupi, V.; Guglielmino, E. Non linear finite element simulation of explosive welded joints of dissimilar metals for shipbuilding applications. Ocean Eng. 2018, 160, 346-353. [CrossRef]

9. Kaya, Y. Microstructural, mechanical and corrosion investigations of ship steel-aluminum bimetal composites produced by explosive welding. Metals 2018, 8, 544. [CrossRef]

10. Findik, F. Recent developments in explosive welding. Mater. Des. 2011, 32, 1081-1093. [CrossRef]

11. Xie, M.X.; Shang, X.T.; Zhang, L.J.; Bai, Q.L.; Xu, T.T. Interface characteristic of explosive-welded and hot-rolled TA1/X65 bimetallic plate. Metals 2018, 8, 159. [CrossRef]

12. Topolski, K.; Szulc, Z.; Garbacz, H. Microstructure and properties of the Ti6Al4V/Inconel 625 bimetal obtained by explosive joining. J. Mater. Eng. Perform. 2016, 25, 3231-3237. [CrossRef]

13. Borrisutthekul, R.; Yachi, T.; Miyashita, Y.; Mutoh, Y. Suppression of intermetallic reaction layer formation by controlling heat flow in dissimilar joining of steel and aluminum alloy. Mater. Sci. Eng. A 2007, 467, 108-113. [CrossRef]

14. Gao, M.; Chen, C.; Mei, S.W.; Wang, L.; Zeng, X.Y. Parameter optimization and mechanism of laser-arc hybrid welding of dissimilar Al alloy and stainless steel. Int. J. Adv. Manuf. Technol. 2014, 74, 199-208. [CrossRef] 
15. Bouche, K.; Barbier, F.; Coulet, A. Intermetallic compound layer growth between solid iron and molten aluminium. Mater. Sci. Eng. A 1998, 249, 167-175. [CrossRef]

16. Wang, P.F.; Chen, X.Z.; Pan, Q.H.; Madigan, B.; Long, J.Q. Laser welding dissimilar materials of aluminum to steel: an overview. Int. J. Adv. Manuf. Technol. 2016, 87, 3081-3090. [CrossRef]

17. Chen, S.H.; Huang, J.H.; Ma, K.; Zhao, X.K.; Vivek, A. Microstructures and mechanical properties of laser penetration welding joint with/without Ni-Foil in an overlap steel-on-aluminum configuration. Metall. Mater. Trans. A 2014, 45A, 3064-3073. [CrossRef]

18. Shabadi, R.; Suery, M.; Deschamps, A. Characterization of joints between aluminum and galvanized steel sheets. Metall. Mater. Trans. A 2013, 44A, 2672-2682. [CrossRef]

19. Sun, J.H.; Yan, Q.; Gao, W. Investigation of laser welding on butt joints of $\mathrm{Al} /$ steel dissimilar materials. Mater. Des. 2015, 83, 120-128. [CrossRef]

20. Dharmendra, C.; Rao, K.P.; Wilden, J.; Reich, S. Study on laser welding-brazing of zinc coated steel to aluminum alloy with a zinc based filler. Mater. Sci. Eng. A 2011, 528, 1498-1503. [CrossRef]

21. Kouadri-David, A.; PSM Team. Study of metallurgic and mechanical properties of laser welded heterogeneous joints between DP600 galvanised steel and aluminium 6082. Mater. Des. 2014, 54, 184-195. [CrossRef]

22. Li, L.Q.; Chen, Y.B.; Wang, T. Research on dual-beam welding characteristics of aluminum alloy. Chin. J. Lasers 2008, 35, 1784-1788. [CrossRef]

23. Li, C.L.; Fan, D.; Wang, B. Characteristics of TIG arc-assisted laser welding-brazing joint of aluminum to galvanized steel with preset filler powder. Rare Met. 2015, 34, 650-656. [CrossRef]

24. Sierra, G.; Peyre, P.; Deschaux-Beaume, F.; Stuart, D.; Fras, G. Steel to aluminum key-hole laser welding. Mater. Sci. Eng. A 2007, 447, 197-208. [CrossRef]

25. Fabbro, R. Melt pool and keyhole behaviour analysis for deep penetration laser welding. J. Phys. D Appl. Phys. 2010, 43, 445-451. [CrossRef]

26. Milberg, J.; Trautmann, A. Defect-free joining of zinc-coated steels by bifocal hybrid laser welding. Prod. Eng. Res. Dev. 2009, 3, 9-15. [CrossRef]

27. Iwase, T.; Sakamoto, H.; Shibata, K.; Hohenberger, B.; Dausinger, F. Dual-focus technique for high-power Nd:YAG laser welding of aluminum alloys. In SPIE High-Power Lasers in Manufacturing; Chen, X.L., Fujioka, T.M., Matsunawa, A., Eds.; Advanced High-Power Lasers and Applications: Osaka, Japan, 1999; pp. 348-358.

28. Blackburn, J.E.; Allen, C.M.; Hilton, P.A.; Li, L. Dual focus Nd:YAG laser welding of titanium alloys. Lasers Eng. 2012, 22, 279-282.

29. Gref, W.; Russ, A.; Leimser, M.; Dausinger, F.; Huegel, H. Double-focus technique: influence of focal distance and intensity distribution on the welding process. In First International Symposium on High-Power Laser Macroprocessing; LAMP: Osaka, Japan, 2002. [CrossRef]

30. Ma, G.L.; Li, L.Q.; Chen, Y.B. Effects of beam configurations on wire melting and transfer behaviors in dual beam laser welding with filler wire. Opt. Laser Technol. 2017, 91, 138-148. [CrossRef]

31. Hansen, K.S.; Olsen, F.O.; Kristiansen, M.; Madsen, O. Joining of multiple sheets in a butt-joint configuration using single pass laser welding with multiple spots. J. Laser Appl. 2015, 27. [CrossRef]

32. Xie, J. Dual beam laser welding. Weld J. 2002, 81, 223-230.

33. Hsu, R.; Engler, A.; Heinemann, S. The gap bridging capability in laser tailored blank welding. Laser Inst. Am. 1998, F224-F231. [CrossRef]

34. Laukant, H.; Wallmann, C.; Korte, M.; Glatzel, U. Flux-less joining technique of aluminum with zinc-coated steel sheets by a dual-spot-laser beam. Adv. Mater. Res. 2005, 6-8, 163-170. [CrossRef]

35. Shi, Y.; Zhang, H.; Takehiro, W.; Tang, J.G. CW/PW dual-beam YAG laser welding of steel/aluminum alloy sheets. Opt. Lasers Eng. 2010, 48, 732-736. [CrossRef]

36. Chen, S.H.; Zhai, Z.L.; Huang, J.H.; Zhao, X.K.; Xiong, J.G. Interface microstructure and fracture behavior of single/dual-beam laser welded steel-Al dissimilar joint produced with copper interlayer. Int. J. Adv. Manuf. Technol. 2016, 82, 631-643. [CrossRef]

37. Cui, L.; Chen, B.X.; Chen, L.; He, D.Y. Dual beam laser keyhole welding of steel/aluminum lapped joints. J. Mater. Process. Technol. 2018, 256, 87-97. [CrossRef] 
38. Mohammadpour, M.; Yazdian, N.; Yang, G.; Wang, H.P.; Carlson, B.; Kovacevic, R. Effect of dual laser beam on dissimilar welding-brazing of aluminum to galvanized steel. Opt. Laser Technol. 2018, 98, 214-228. [CrossRef]

39. Xia, H.B.; Zhao, X.Y.; Tan, C.W.; Chen, B.; Song, X.G.; Li, L.Q. Effect of Si content on the interfacial reactions in laser welded-brazed Al/steel dissimilar butted joint. J. Mater. Process. Technol. 2018, 258, 9-21. [CrossRef]

40. Springer, H.; Kostka, A.; Payton, E.J.; Raabe, D.; Kaysser-Pyzalla, A.; Eggeler, G. On the formation and growth of intermetallic phases during interdiffusion between low-carbon steel and aluminum alloys. Acta Mater. 2011, 59, 1586-1600. [CrossRef]

41. Zhang, H.T.; Feng, J.C.; He, P.; Hackl, H. Interfacial microstructure and mechanical properties of aluminium-zinc-coated steel joints made by a modified metal inert gas welding-brazing process. Mater. Charact. 2007, 58, 588-592. [CrossRef]

42. Balogh, Z.; Schmitz, G. Diffusion in Metals and Alloys; Laughlin, D.E., Hono, K., Eds.; Physical Metallurgy: Oxford, UK, 2014; pp. 387-559.

(C) 2018 by the authors. Licensee MDPI, Basel, Switzerland. This article is an open access article distributed under the terms and conditions of the Creative Commons Attribution (CC BY) license (http://creativecommons.org/licenses/by/4.0/). 